\title{
WAGING WAR FROM REMOTE CUBICLES: HOW WORKERS COPE WITH TECHNOLOGIES THAT DISRUPT THE MEANING AND MORALITY OF THEIR WORK
}

\author{
Madeleine Rauch \\ Copenhagen Business School \\ Department of Strategy and Innovation \\ Kilenvej 14, 3. \\ 2000 Fredriksberg, Denmark \\ Email: mra.si@cbs.dk
}

\author{
Shahzad (Shaz) Ansari \\ Cambridge Judge Business School \\ University of Cambridge \\ Trumpington Street \\ Cambridge CB2 1AG, UK \\ Email: s.ansari@jbs.cam.ac.uk
}

Accepted for publication at Organization Science

Acknowledgments: We are indebted and grateful to the individuals allowing us a glimpse into the reality of working under extreme contexts by giving us access to their most private thoughts. The views and conclusions contained herein are those of the authors and do not necessarily reflect the views of the U.S. government or U.S. Air Force. We are indebted to the excellent guidance by the Special Issue Editors and the two reviewers that helped us to sharpen our manuscript. We also thank Steve Barley, Woody Powell, Anne-Laure Fayard, Stine Grodal, Marc Ventresca, Xu Li, Wolf Uhlbach, Bob Eberhart, Mareike Moehlmann, Stella Pachidi, Ella Hafermalz, and Renate Kratochvil, and seminar participants at the Nature of Work-Workshop at Stanford in 2021, DRUID 2021, SMS 2021, UC Davis Qualitative Conference 2021, 'Nets and Orgs' at Stanford, HEC Lausanne, and University of Edinburgh for comments on earlier versions of this manuscript. An earlier version has also won the Best OMT Paper Award at the $81^{\text {st }}$ Annual Meeting of the Academy of Management 2021. 


\title{
WAGING WAR FROM REMOTE CUBICLES: HOW WORKERS COPE WITH TECHNOLOGIES THAT DISRUPT THE MEANING AND MORALITY OF THEIR
}

\section{WORK}

\begin{abstract}
Technologies are known to alter social structures in the workplace, reconfigure roles and relationships, and disrupt status hierarchies. However, less attention has been given to how an emerging technology disrupts the meaning and moral values that tether people to their work and render it meaningful. To understand how workers respond to such an emerging technology, we undertook an inductive, qualitative study of military personnel working in unmanned aerial vehicles, or drone operations, for the U.S. Air Force. We draw on multiple data sources, including personal diaries kept by personnel involved in drone operations. We identified three characteristics of drone technology: 'remote-split' operations, remote piloting of unmanned vehicles, and interaction through iconic representations. Our analysis suggests that drone technology has revolutionized warfare by 1) creating distanciated intimacy, 2) dissolving traditional spatio-temporal boundaries between work and personal life, and 3) redefining the legal and moral parameters of work. Drone program workers identified with these changes to their working environment in contradictory ways, which evoked emotional ambivalence about right and wrong. However, their organization gave them little help in alleviating their conflicting feelings. We illuminate how workers cope with such ambivalence when a technology transforms the meaning and morality of their work. We extend theory by showing that workers' responses to a changed working environment as a result of a remote technology are not just based on how the technology changes workers' tasks, roles and status, but also on how it affects their moral values.
\end{abstract}

Keywords: Emerging technology, drones, emotional ambivalence, emotions, remote control, moral emotions, war, military. 


\section{INTRODUCTION}

"It is forbidden to kill; therefore, all murderers are punished unless they kill in large numbers and to the sound of trumpets." (Voltaire)

Emerging technologies can occasion significant transformations in work, disrupt social structures and status hierarchies in the workplace, and alter the boundaries of expert authority (Barley 1986, 1990; Barley, Bechky, and Milliken 2017; Barley and Kunda 2001; Barrett et al. 2012). For instance, computational infrastructures and digital connectivity may render workplace behaviors hypervisible (Leonardi and Barley 2010; Leonardi and Treem 2020) and generate novel forms of coordination and control (Faraj, Pachidi and Sayegh 2018; Kellogg, Valentine and Christin 2019), which necessitate abrupt changes in required behaviors and organizing processes. However, emerging technologies that redefine the entire context of work may also disrupt the moral values that tether people to their work and render it meaningful. When these values no longer provide guidance in this "new normal," workers become unsure about how to act appropriately or who they should be (Petriglieri et al. 2019). This may be particularly the case in ideology-driven organizations, where workers "over-identify" with their work and hold their professional values sacred (Elsbach 1999; Ross et al. 2010), even regarding their work as a "calling" (Bunderson and Thompson 2009).

While studies have shown that changes to deeply held values of work lead people to respond in different ways to emerging technologies (e.g., forensic scientists responding to DNA technology) (Bechky 2020), we still have only a limited understanding of how workers "at the coalface" (Barley 2019) respond emotionally. Also, while studies have shown how emerging technologies become entangled with social practices, leading to "cognitive overload" and loss of trust and evoking emotions such as awe, angst, stress, or insecurity (Bailey, Leonardi and Barley 2012; Barley, Meyerson and Grodal 2011; Hinds and Bailey 2003; Mazmanian et al. 2013), less attention has been given to workers' emotional appraisals of new technologies and their responses to them, especially when these are technologies that unsettle the core meaning and moral foundations of their work. Moreover, in highly regulated "masculine" organizational contexts characterized by strong "feeling rules," toughness, self-reliance, and a preference for rationality over emotionality (Kunda 
2006; O’Neill and Rothbard 2017), workers have little organizational support to vent or share their feelings and to adjust collectively to the new norms of work.

To understand how workers experience and respond to emerging technologies that disrupt the sacred meaning and values of work in contexts with strong "feeling rules," we conducted an inductive study of military personnel operating unmanned aerial vehicles (UAVs), or drones, for the U.S. Air Force. Drone technology has revolutionized conventional warfare by replacing costly invasion of foreign territories with surgical attacks conducted remotely on selected targets (Elish 2018; Schwarz 2018). While the technology is regarded as morally justifiable for enabling a "virtuous" war (Boyle 2015), it is also morally contentious. It thus provides an ideal basis for studying workers' affective responses to an emerging technology. Our analysis reveals three key characteristics of the technology; remote-split operations, remote piloting of unmanned vehicles, and interaction through iconic representations that allow 1) "distanciated intimacy," 2) dissolve traditional spatial and temporal boundaries between professional and civilian life, and 3) redefine the moral and legal parameters of work. We explain how the technology creates conflicting feelings, and how service members - both experienced and new recruits - respond in different ways to the new technology. These characteristics make drone technology different to other technologies (e.g. 3D models and simulations), where workers operate within rather than through a representation and do not need to connect with the objects and humans being represented (Bailey et al. 2012).

Our findings allow us to make three contributions. First, we show how emerging technologies disrupt the meaning and moral values of work and evoke different emotional responses in workers. Previous studies have shown how new technologies upend the roles and relationships in work and disrupt status hierarchies (e.g., Bailey et al. 2012; Barley 1986; 2020; Barrett et al. 2012), and also how they evoke emotions such as anxiety, stress, or fear (Barley et al. 2011; Hinds and Bailey 2003). While these studies typically do not consider the moral implications that a technology may have for work, we show how technologies can problematize the meaning and morality of work and evoke feelings about right and wrong. By foregrounding how meanings, moral values and virtues tether people to their work (e.g., Bechky 2020; Evans 2021; von 
Krogh et al. 2012), we show that responses to a changed working environment as a result of an emerging technology involve complex dynamics and are infused with moral emotions.

Second, we explain how workers respond to a type of virtual technology that allows them to manipulate objects remotely through representations. Such representations can be either symbolic (information conveyed through symbols) or iconic (information conveyed through real-time pictures) (Bailey et al. 2012: 1487). By elucidating how remote control disrupts work, we respond to a call by Bailey et al. (2012: 1488), who noted that "even though remote control is far from uncommon, it has attracted less attention among students of work and organizing (...)." Studies of remote work have described how different types of virtual representation may require changes in the way work is organized and can disrupt trust and power relationships between managers and virtual operators (Barley et al. 2012; Beane 2018; Perrow 1983; Zuboff 1988). We extend this work by explaining how remote control may not just disrupt trust and power hierarchies but can also interfere with people's ability to realize their own values (Rosso et al. 2010), and how restoring meaning to their work in the new working environment is not just a cognitive but also an affective process.

Third, we introduce a novel methodology - analysis of workers' personal diaries - to shed light on the emotional side of coping with emerging technologies in working environments in which people tend to suppress their emotions (O’Neill and Rothbard 2017). While writing personal diaries, is a time-honored and culturally sanctioned way of expressing one's innermost feelings (Klein and Boals 2001; Rauch and Ansari 2021) and has been described as a "technology of the self" (Foucault 1982), we show the value of diaries in capturing the strong emotions that individuals experience but try to control, regulate, or suppress at work. Diaries thus serve as a complement to interviewing and observing people's behaviors when one is seeking to capture the innermost emotions of those individuals and to decode non-verbal emotional cues.

\section{THEORETICAL MOTIVATIONS}

It is not uncommon for emerging technologies to reconfigure task interdependencies, alter social structures, disrupt roles and relationships, and change status hierarchies, with profound ramifications for workers, organizations, and even wider society (Barley 1990; Barley et al. 2017; Pachidi et al. 2020, von Krogh 2018). New digital technologies have enabled different types of virtual work (Bailey et al. 2012). 
While virtual teams (e.g., people connected by email) may not significantly alter existing roles in an organization, remote control (e.g., firemen using robots to help victims in burning buildings) may lead to a change in the division of labor; it may, for example, enable operators to make decisions traditionally reserved for managers (Zuboff 1988). Similarly, simulation (e.g., the use of computer models to train pilots) also create challenges in the workplace, as people may confuse the models with reality. Management may fail to distinguish between different types of virtual work and may overlook the new organizational dependencies that develop, thereby impairing the organizing and execution of work (Bailey et al. 2012).

When new technologies change what people do, and how they do their work then affects their interactions, this disrupts the division of labor within the organization and its social structure and status hierarchies (Barley 2020). One study showed, for example, that the arrival of a CT scanner in a hospital changed the status of radiologists and technologists and the authority they wielded in the organization (Barley 1986, 1990). Similarly, Barrett et al. (2012) showed how introducing a pharmacy dispensary robot into a hospital helped the work of higher-status physicians, but the robot's programming impeded the work of lower-status technical assistants. Thus, the adoption of new technologies not only changes the nature of work but can also disrupt existing hierarchies, creating new sources of power and status.

While scholars have developed a detailed understanding of how technologies affect power and status within the workplace, relatively few studies have considered how technologies can impinge on the morality or virtues of work (Brusoni and Vaccaro 2017; Evans 2021; von Krogh et al. 2012). This suggests there is a need to go beyond power and status dynamics to understand the impact of technology on organizations and work (Bechky 2020). Work values are defined as "the end states people desire and feel they ought to be able to realize through working" (Nord et al. 1990: 21), which bring meaning and purpose to work (Frankl 1959). The meaning and moral values of work have a profound effect on how people respond to new technologies that change what they view as being fundamental to their work. For instance, von Krogh et al. (2012) explain how the introduction of commercial software licenses at MIT undermined the moral values that underpinned the work of local software developers. One of these developers then went on to set up the Free Software Foundation (the precursor to open source) in order to preserve the morality of the developers' work. Similarly, 
when DNA profiling was introduced into forensic science, different occupational groups responded in line with the values they held with regard to their work (Bechky 2020). Firearms examiners and narcotics experts interpreted DNA profiling as an affront to their values of craft-based judgement and were resistant to changing their way of working. In contrast, toxicologists embraced the technology as they perceived it to be consistent with their desire to avoid potential errors (Bechky 2020). The specific work values held by these occupational groups, and which informed their everyday practice, were of more significance in shaping their response to the technology than the status and power of each group (Bechky 2020). Indeed, people interpret new technologies within the framework of the values that inform their work (Fayard et al. 2017).

Emerging technologies can create an unfamiliar context in which people lose a sense of relatedness to certain aspects of their new work and may no longer be able to be true to the values that they hold dear (Petriglieri et al. 2019). Such a loss of meaning and moral values evokes strong emotions (Voronov and Vince 2012; Voronov and Weber 2016; Zietsma et al. 2018). However, research on work tends to skate over affective processes in favor of cognitive ones, even though both types of processes are intertwined in shaping behavioral responses to change (Oreg et al. 2018). Values animate the "passions and fears" that produce and sustain our practices (Friedland 2018: 515). Such emotions are likely to be even stronger when people regard their work not just as a "job" but as an end in itself, or indeed as a "calling" - defined as a mission to undertake activities that are felt to be morally, socially, and personally significant (Kunda 2006; Wrzesniewski 2012). Indeed, professional work is often characterized by "an ideology serving some transcendent value asserting greater devotion to doing good work than to economic reward" (Freidson 2001: 180). For instance, Von Krogh et al. (2012) argue that it is not economic incentives that drive open source software developers to develop high-quality software but a desire to work on something that they view as moral and virtuous.

While any kind of work can be a calling, much of the organizational research on callings has focused on work that might be termed "prosocial," such as nursing or zoo keeping, where a sense of transcendent meaning comes with the costs and burden of sacrifice (Bunderson and Thompson 2009). Less is known about the challenges people face and have to negotiate in other kinds of work when aspects of their work clash with individual values that are fundamental to how they identify with their work. This then requires them to 
construct new meanings for their work (Schabram and Maitlis 2017). Regarding work as a calling is often seen in organizations with strong cultures and ideologies, where work matters a great deal to people (O’Neill and Rothbard 2017). In such organizations, workers experience more powerful negative emotions if radical changes upset the meaning and values on which their work has previously been based (Thompson and Bunderson 2003). However, we still need a better understanding of how workers respond to technologies that evoke strong emotions as a result of disruption.

\section{Technologies, Emotions, and Contexts}

Technology studies have addressed how technologies evoke emotions such as stress and anxiety (Barley et al. 2011; Bailey et al. 2012; Hinds and Bailey 2003). For example, employees (e.g., at Uber and eBay) may experience social isolation arising from being controlled and exploited by the decisions made by "algorithm bosses" (Curchod et al. 2020; Möhlmann et al. 2020). However, they have tended to overlook the moral emotions that can arise when technologies infringe the values of work (Evans 2021). Moral emotions pertain to feelings of approval and disapproval (Kroll and Egan 2004), such as "compassion for the unfortunate or indignation over injustice" (Jasper 2011:287). As values give people a moral compass, guiding their behavior in terms of what is right and wrong (Schwartz 1992), acting in accordance with those values gives individuals a sense of assurance that "they have done the right things, thereby minimizing guilt, anxiety, regret, and other forms of moral distress" (Baumeister and Vohs 2002: 610).

For example, the use of stem cell technology to develop regenerative medicine that can help cure diseases that involve cell disorders (e.g., Alzheimer's disease) has been justified by leading scientists and laboratories directors as a moral imperative for the advancement of medicine (Evans 2021). At the same time, it has also provoked moral disapproval in the media and in public policy settings, and even among scientists who advocate developing alternative cell models that do not involve the use of embryos. The moral issue arises from debates that revolve around when and how personhood should be attributed to these embryos. Similarly, while the use of artificial intelligence (AI) can create anxiety among workers when they fear they will lose their jobs, it can also arouse moral emotions. In policing, for example, such emotions may arise because of the way technology can disrupt traditional policing values, affecting the autonomy of individual 
officers, for example, and their reliance on personal interactions with the community (Brayne 2017). AI is sometimes regarded as morally problematic because it can reinforce existing social biases against people from disadvantaged background and elicit moral emotions of approval and disapproval.

In sum, the introduction of an emerging technology can change the core meanings and values that underpin how people identify with their work. They may struggle not only to relate to their work but also with its morality. As those in strong organizational cultures over-identify with the values of their work, when these values are overturned by a new technology, strong emotions are evoked. In some organizations with strong feeling rules, no organizational support is provided to help people deal with their emotions. So, if such organizations provide no support for their employees to form new meaning and values collectively, how may these individuals respond to the strong emotions created by a new technology?

\section{METHODOLOGY}

To address this issue, we draw on an inductive approach to study individuals in an organizational setting in which an emerging technology has revolutionized modern warfare: the Unmanned Combat Aerial Vehicles (UCAV) program of the United States Air Force. Our primary data source draws on 43 personal diaries kept by military professionals working for the UCAV program. Personal diaries are intimate journals in which individuals record their lived experiences and their personal reflections and opinions. We complemented these diaries with interviews, ethnographical observations, and archival documents.

\section{Case Selection and Research Site: United States Air Force "Drone Program"}

The U.S. Air Force is the "aerial and space warfare service branch" of the U.S. Armed Forces, which forms part of the Department of the Air Force and belongs to the Department of Defense. The core activities of the Air Force range from providing air and space superiority, global integrated intelligence, surveillance, and reconnaissance to rapid global mobility and strike capability. Besides its air and space operations, the Air Force provides air support for land and naval forces and aid for recovery missions in the field. The stated mission is "Fly, fight, and win ... in air, space, and cyberspace" (Internal document 29).

In line with its mission, the Air Force has intensively developed its UAV program, in particular since its deployment as an immediate response to the attacks of 9/11. At that time President George Bush presided 
over what we know as the modern drone war, which began in 2004. With a decline in public support for the war on terror due to the mounting death toll of soldiers, President Obama promised to bring U.S. ground wars to an end. Drones presented a "technological" way of confronting the global threat of asymmetric warfare or terrorism. By the end of Obama's eight-year tenure as president, 542 strikes had been recorded, and some news outlets had named him the "President of Drones" (Rogers 2019). Under President Trump, drone strikes continued in the quest for "precision warfare" to win global wars with little risk to American lives, and the killing of Iran's most senior general in a 2020 attack by a "Reaper drone" was the first time the U.S. had used the technology to kill another country's military commander on foreign soil (United Nations 2020). Given the growing importance of the drone program for the U.S. military, the need for qualified personnel to fly, operate, and maintain UAVs has increased dramatically.

\section{Data Sources}

Our principal data set comprises the personal diaries of individuals working on the drone program in the Air Force. We also conducted interviews with the diarists to understand their experiences, asked followup questions to explore what they had written in their diaries, conducted ethnographical observation in the field, and studied internal documents. We conducted ethnographical observation through visits to a military base in the U.S., to get a feel for the situation in which these diaries were written (see Table 1). In the military there is dislike of the word "drone," and the term "unmanned RPAs" (remotely piloted aircraft) is used instead. Here we use the popular term, drones.

Diaries: Diaries are a form of personal document (Taylor and Bogdan 1984). Although data obtained from diaries have both strengths and weaknesses, a key strength of diaries is that they provide an insider account of a situation (e.g., Rauch and Ansari 2021). The diarists recorded in situ their experiences, feelings, and personal accounts, including reflections on their work, events, and lives. We obtained consensual access to the diaries written by workers. The diaries were written voluntarily, and the organization did not encourage, promote, or have access to them. The reasons for writing a diary were strictly personal, with some diarists describing it as a "a way to talk to at least somebody which I picked up during my military time" or as "a self-improvement technique that I read about online." 
We used a snowball sampling approach (Biernacki and Waldorf 1981), i.e., "a study sample through referrals made among people who share or know of others who possess some characteristics that are of research interest" (p. 141). Given the sensitive nature of the information, we did not ask diarists directly to participate (e.g., by cold calling) but relied instead on unsolicited referrals from individuals who encouraged other colleagues to participate by sharing their diaries and personal conversations. We made initial contact with the diarists through shared downtime on a military base in South Asia and through our research interest in studying people's diaries in extreme contexts. In personal conversations, a group of workers revealed that they also kept diaries, which sparked discussion about the potential similarities between diarists working in extreme contexts. As we had already collected more than 100 diaries from individuals from outside the military (e.g., aid workers), respondents came round to the idea of sharing their diaries with us, making statements such as "I bet those pencil pushers [medical personnel] have boring stories compared to us."

Our experience of doing research in extreme settings, including spending time in Afghanistan visiting military establishments, gave us legitimacy in terms of our ability to relate to the military personnel and to "speak the same language,". It also helped to reinforce our independent role as researchers (we have no institutional ties to the Air Force, nor are we involved in any activity with it). We anonymized the data to protect the diarists' identities and those of the people they talked about. We thus refrain from referring in our study to specific missions, procedures, or individuals. All handwritten diaries (14) were transcribed professionally. The data were imported into the qualitative text analysis software NVivo for further analysis.

Interviews: After reading the diaries several times, we invited the diarists off base for semi-formal, indepth interviews. We used semi-structured interviews lasting between 45 and 120 minutes. We used a critical incident method, asking the diarists about their individual experiences and memorable events (Chell 2004). Overall, we conducted 43 interviews, which were recorded and transcribed verbatim. For the four diarists who preferred not to be recorded, we took detailed notes on the contents of the interviews.

Ethnographical observation: To understand the uniqueness of the context, one author obtained consent to visit a military base in the U.S. several times over the course of study. She attended "preparatory" meetings and training sessions in order to prepare herself for the visit and familiarize herself with the 
terminology used in the field. During these field visits, she conducted and recorded "casual conversations" with personnel other than the diarists to obtain immediate reflections on their activities, recording these as field notes. She also took part in friendly gatherings (e.g., barbeques and a local baseball game), which were also recorded as field notes within 24 hours.

Documents: We examined internal documents pertaining to training syllabuses, pamphlets, and presentations. In total, we studied 2,937 documents, including annual reports, pre-deployment information, mission briefings, reports on preventing post-traumatic stress disorder (PTSD), and redacted dissertations written by military personnel (e.g., on the MQ-9 Reaper). We also examined reports covering the legal and ethical aspects such as on the principles, standards, and procedures for authorizing drone warfare.

\section{Data Analysis}

We followed a theoretically sensitized inductive approach (Glaser and Strauss 1967; Strauss and Corbin 1998). We iterated between data, emerging themes, and theories throughout our analysis (Locke 2001). We were intrigued by how an emerging technology altered traditional warfare. Our hunch pointed to changes in the nature of work and the mixed feelings these would generate. We followed a five-step analysis process.

First, we familiarized ourselves with the specificities of working in the "drone war," delving into work on the military and societal debates on this topic. We consulted news articles and press releases from organizations such as the United Nations and Human Rights Watch. We also engaged with drone war historians and read books such as Dirty War, Predator, and The Assassination Complex, which drew on whistleblower stories and ethnographical observations of working in a combat zone and the emotional distress this creates. We used NVivo to identify key themes and sub-themes.

Second, we elucidated the changes in the nature of warfare. We created tables and timelines that showed background information, important key events, and the mission experiences (Van de Ven and Poole 1990) of the different diarists. The development of these chronologies revealed how drones had fundamentally changed the core meaning, and values of work for those concerned, generating mixed feelings. For example, workers stated that they felt a sense of pride in the technological capabilities offered by drones (e.g., protecting the troops on the ground) but also suffered moral distress when civilians and children were 
injured or killed in drone attacks. This early analysis also revealed several tensions that respondents described as a "paradox," such as being on an Air Force base located in the U.S. but at the same time also entrenched in missions in, for example, Afghanistan, or Yemen. In their words, this was about being "18 inches away" from the battlefield but having "no skin in the game." We began our analysis with open coding of the database and engaged in a first round of in vivo coding by staying true to the terms and phrases of our respondents. The frequent and explicit use of the terms "close by and far away," and "right and wrong" facilitated the selection of passages in texts. We categorized the in vivo codes into a set of categories for subsequent comparative analysis (Locke 2001).

Third, we collapsed similar codes and created first-order categories, which enabled us to move from provisional to advanced categories (Locke 2001). We noticed that workers agonized about being "pulled" and "torn" between a sense of pride in making the world a safer place and shame between making the world a safer place and having no skin in the game. Such statements about mixed emotions led us to probe further into what triggered this emotional ambivalence and how workers responded, leading us back to the specific characteristics of this technology (i.e., remote-split operations, remote piloting of unmanned vehicles, and interaction through iconic representations). We examined how different characteristics of the remote control technology affected the core meaning, and values of work that triggered emotional ambivalence by (1) creating distanciated intimacy, (2) disrupting spatio-temporal boundaries, and (3) changing the moral and legal parameters of work. We noticed how these changes affected how workers identified with their work and raised questions like “Am I still a soldier?” (Diary 20) and “who am I?” (Interview 05).

Fourth, we explored the workers' response strategies. Drawing on the diaries written in situ gave us insights into the world of individuals who needed to exert emotional control at work. We also recognized differences in the strategies used to respond to emotional ambivalence. We identified four different strategies that changed over time: (1) falling back on previous values (unconditional re-identification), (2) creating new meaning and regarding new values in a positive light (reconciled identification), (3) avoiding issues relating to the meaning and morality of work (sidestepping identification), and (4) failing to reconcile oneself to the change and leaving the organization (estrangement). We observed that, depending on the length of their 
affiliation to the organization, some individuals found it easier to leave than others. Recent recruits found this less difficult than those who had spent a long time in the military. We sought patterns in the data to discern differences between the workers and their response strategies (see Table 3). Iterating between data and theory (Corbin and Strauss 1990), we compared our respondents' reports, identifying differences across time and between groups and generating theory-driven second-order categories.

Finally, we collated our derived categories into a theoretical model in order to understand how individuals manage emotional ambivalence. We conducted member checks (Lincoln and Guba 1985) for our findings, which we discussed with various diarists on several occasions, both during and after data collection. Following Pratt (2008), we provide quotations and representations of the diarists' personal accounts, not only in the main text but also in tables (see Table 2).

-------Insert Tables 1, 2, and 3 here-------

\section{FINDINGS: THE EMOTIONAL SIDE OF RESPONDING TO AN EMERGING TECHNOLOGY}

We explore how the introduction of drones and the changes this brought to the way service personnel perceived their work created mixed feelings. We illustrate some key characteristics of the emerging technology and describe the changes it brought to the core meaning, and values of work. Lastly, we identified four different response strategies that workers deployed to cope with the changes in their work.

\section{Introduction of an emerging technology}

With geopolitical developments such as the withdrawal of ground troops from Iraq and Afghanistan, the U.S. reliance on the drone program to counter terrorism has grown. A UN report (2020) refers to this progressive transformation of modern warfare, stating that drones are "[...] now more capable of targeted killings both near and far, drones are becoming stealthier, speedier, smaller, more lethal and operable by teams located thousands of kilometers away" (p. 5). Key characteristics of this technology include:

Remote piloting of unmanned vehicles: The drone program has removed the need for direct physical deployment of personnel to an active war zone. Instead, drones have "unmanned" the aircraft, so that the pilot is no longer in a physical cockpit but in a virtual cockpit back on American soil. Capable of traveling at $300 \mathrm{~km} /$ hour and staying airborne for over 20 hours, drones can collect extensive data (e.g., on the movements 
of troops or insurgents), and can be used to listen in to private conversations conducted on mobile phones and computers. Mostly stationed in the U.S., the pilot and crew members (e.g., sensor operators are now situated in a cockpit on the ground - the Control Station - from which they control drones. A pilot described how this works:

"The cockpit I sit physically in Silver State [Nevada]. We are about 2,000 feet above sea level, but I control $[\ldots]$ a weird-shaped gray flying object that looks like a grey shark that is cruising 30,000 feet above Afghan territory. With the help of lots of clunky monitors I am live on the ground, and with some joystick movements and clicks here and there I can see activity and movements." (Interview 10)

This geographical proximity, which was also referred to as "being 18 inches from the battlefield" (Field note 60) - a reference to the distance between their eyes and their monitors in the Control Station - has allowed a "new Big Brother technology-enabled era of warfare" (Interview 12) and a "visual representation of war on screens" (Diary 11). Instead, drone program workers see themselves as "the eye in the sky" (Diary 20) or refer to the drone as "being the new national bird in Afghanistan" (Informal conversation 51).

Remote-split. The remote-split refers to the highly interdependent system of actors and technology that allows operators stationed at a location thousands of miles away to engage in "intelligence, surveillance, and reconnaissance" (ISR). These remote-split drone operations involve a diverse set of actors and draw on various networks of humans and technologies (e.g., satellite links and undersea cables) distributed around the globe, and activities are split (i.e., divided) between multiple actors in a network (Elish 2017). A drone unit is simply part of a remotely piloted aircraft system. In one official report, this is described as follows:

"It is actually a system, not just an aircraft, which consists of four aircraft (with sensors and weapons), a GCS (Ground Control Station), a Predator Primary Satellite Link (PPSL), and spare equipment along with operations and maintenance crews for 24-hour operations" (USAF 2011:3)

Given the complex structure of remote-split operations, there is an increasing need for close collaboration across units. To operate one drone (e.g., the MQ9) at least four sorties are needed, with four aircrafts in a 24hour shift. The deployment involves 210 personnel, ranging from those close to the zone of operations (approximately 60), to those based in the control room (14 pilots, 14 sensor operators, 56 intelligence analysts, and several legal experts) (Kreuzer 2014: 169). In addition to having immediate contact with at least two colleagues in the cockpit in the Ground Control Station, crew members regularly communicate with 
information analysts and screeners, often stationed in Virginia or Florida, as well as with other personnel in different time zones (including those closer to the battlefield) to discuss mission-critical aspects. Such coordination is vital, as the Air Force contractor crew stationed at local airbases, (e.g., Afghanistan) is responsible for drone take-offs and landings before "handing over" the aircraft to the pilot and his crew sitting in the U.S. (Internal document 198). A pilot stated:

"The most difficult part before was starting and landing on aircraft carriers but now I just take over once airborne. What I am most concerned with is how long the bird can run, as sometimes we just take over from the crew and only a few hours are left before it has to return to the local base to get recharged. It is a lot of coordinating, a lot more than what I was used to before." (Field note 64)

Interaction through iconic representations. A third key characteristic of this new technology is that it entails interaction through iconic representations. Sitting in cubicles and equipped with computer monitors, operators are connected to other sections of the military to gather, process, and analyze mission-critical information. This interdependence between technology and human activities is illustrated in an informal conversation during one of our field visits:

"I have a live feed of all the movement 24/7, 365. Technology plays a much more central role now because it allows interactions with insurgents directly." (Informal conversation 22)

This live interaction through iconic representations is also evident in the transcript of one of few publicly available USAF incident reports. This report provides details of the internet relay chat between the people involved (e.g., the sensor screener, the pilot, the mission coordinator, etc.) as they followed standard procedures such as surveillance movements, accessing potential targets, and making risk assessments:

00:24 (JAG25): Roger those two vehicles they appear to be moving south to the left are they staying close to the green zone or are they moving out in to the open?

00:24 (Slasher03): We are now tracking three vehicles and standby we will give you an update.

00:25 (JAG25): Copy.

00:25 (Slasher03): They're on the move and we will try to get you the distance between them. (...)

03:48 (JAG25): Kirk97, Good copy. If they close distance with our location at [redacted] base, and at Ground force commander's orders we may have them come up, action those targets, and let you use your hellfire for clean-up shot.

03:49 (Pilot): Kirk97, Good copy on that, sounds good.

As illustrated in this excerpt, situations and missions often evolve quickly and change from surveillance to kill-missions, which involve collecting and passing new information from the ground control crew to the 
troops on the ground and vice versa and exchanging intelligence through iconic representations of the

potential targets of attack and of U.S. troops in need of protection. In the words of a drone operator:

"You see your buddies down there moving, or other friendlies and the insurgents, all through monitors displayed across the room. You cannot talk to them directly, there is no sound or smell, you don't feel the heat and weather on the ground, but you are still in the middle of all and interact with them." (Interview 12)

\section{Changes in the core meaning, and values of work}

Disruption of spatio-temporal boundaries. A key aspect of life in the military is "batch" living, where "play" and "work" are one. The drone program has dissolved the strict separation between military and civilian life. It has also changed the relationship to what is known as the "brotherhood," where workers typically spend "24/7 together, eat, work, shit, and party together" (Diary 10) and know "everything about each other from when the cousin of a distant aunt got a new hip, or the brother of grandpa got caught with the Playboy magazine at his retirement home' (Diary 30). Now that they are "not fighting side by side" but are instead "sitting side by side in front of monitors" (Interview 12), workers describe how this has disrupted the traditional separation between civilian and military life. For example, one drone operator said:

"It is a surreal feeling the moment you step out of the control room. Within minutes you are no longer in a combat zone but on your way back home to your family in peaceful America. Maybe doing a quick stop at Walmart to pick up groceries for the BBQ planned or get a slushy. Minutes before you were gathering intel in Pakistan. This transition is the hardest part of the job because one has no such switch button in the head to change from being in Pakistan to your daughter's birthday party in a second later or a fight with your wife because you forgot to take out the trash. We are expected to change from a war setting to happy family life in an instant." (Interview 09)

With the new working arrangements, the typical work schedules of "war fighting changed" (Interview 04).

The schedule at the drone base now involves a minimum eight-hour shift for six days in a row, followed by

three days off. One pilot described the changes in an informal meeting for a coffee off-base:

"Our birds run 24/7, 365 days a year. We are always in combat. There is never an end or a stop or anything. Wasn't it supposed to be that a war has a mission or purpose? If I worked through the pile of targets, there will be a new one. If not in country X, then country Y, without a clear pattern or rationale for me to understand." (Field note 65)

Such examples suggest the concept of war has changed, as workers have moved from short-term

assignments overseas, followed by long "decompression phases" and "time off the war" (Diary 29), to a “constant war at a relentless pace" (Diary 29). In other words, "War becomes my daily job. It is in America's 
backyard." (Diary 30). This often expressed perception of being a "factory war worker instead of a soldier" (Diary 19) has been reinforced by the shift from having a "common enemy" and a clearly defined target (e.g., bring down Saddam) to a perpetual sense of "enduring war." As seen by our interviewees, "The globe became the battlefield" (Interview 09); they were given "very little information" on "why this person ended up on my desk" and lacked a "bigger picture of the mission."

Creation of distanciated intimacy. Drones have allowed workers to form new and different kinds of social relationships with people they are assigned to observe, surveil, or target. Workers described this as "taking part" in local social life through "live footage," and it has also allowed them a peek into the mundane life of locals who appear in the background on their screens. Others described similar experiences of "feeling part of their lives," saying, "I have been watching their family life for a substantial time. I attended the wedding of their second youngest son, the burial of their aunt, and several cousins after one of our strikes" (Diary 19). This creates distanciated intimacy, as reflected in one diary entry:

"Ordinary people aren't that much different to us. Similar problems, fighting with the spouse, smoking, drinking, well, some illegal alcohol. Well, their sense of fashion is, let's say, different but with 100F [38C] I also might wear loose clothing. If you take away those dresses, it could be somewhere in rural Midwest U.S." (Diary 10)

A sensor operator gave an illustration of such social bonding:

"Sometimes it goes even that far, when we are bored during nightshifts when not much is going on, we fly over Michigan [nickname given to a rural area in Afghanistan characterized by lakes] and check up on Kim [Kardashian, nickname given to a flashy local, in reference to a U.S. media personality] and update on her recent boy drama." (Interview 23)

Others reported that this new "closeness" to the battlefield and to the subjects they were surveilling changed the kind of social relationship they had with those people, giving them, for example, a much better understanding of everyday life in those local settings. They also described how, despite the geographical distance, they felt part of the "last minutes of their lives," as they witnessed and followed up on the aftermath of their deaths. An operator described this as follows:

"We sent it [the missile] down and we are live right with the action. [...] For half a minute the monitors are filled with smoke, and nothing is to be seen because of the thick clouds. Only then I see the outcome of the action and things getting moving. Did we get it right? Target alive or dead? Another package [missile] to be sent down? Any other incidents to report? Civilians or children? Chaos?" (Diary 10) 
Changing the moral and legal parameters of work. Given their now much more involved role - which they described as their "Big-Brother-like work" (Interview 20), "front row seats to the action" (Informal talk 43), and the "uncut version of a horror movie" (Diary 40) - workers began to question the morality and legality of what they were doing. One example was the identification of targets. For example, one typical procedure is the assessment of PID (positive identification) to confirm the demographics, including the gender and age of the people on screen to determine whether so-called military-aged men (MAMs) are present and to assess the level of threat. Such classification is crucial as it can determine whether a mission is re-classified from "kill" to "surveillance" or vice versa. One operator noted:

"We have our fixed criteria and tick the boxes with the help of video screeners and lots of people involved calling PID and MAMs. But with the live and constantly developing situation, intel, video feed, radio chatter, IRC, finding accurate answers to this question is complex. [...] But it doesn't always feel like it is the most just version of the truth we are doing here." (Interview 30)

Given the sensitive nature of the work, particularly when younger children (below the age of 12) and females are involved, it is customary to consult with lawyers. This has been a significant change for many, because in conventional warfare fighter pilots already had the "green light" before taking off for their destination. In operations where a missile is to be released from an armed drone, lawyers help to assess the target and advise about potential civilian causalities "until the very last moments" (Interview 12).

There has been increased media coverage of potential violations of international law, breaches of the Geneva Convention, and the ethical and moral implications of drone operations in non-declared war zones. Workers have noticed that public debates about the legal and moral defensibility of drones have intensified, and that there is now discussion of "who" has the right to declare a war and to delineate areas of "active hostility" (Field note 91). An operator reflected what he had seen in a television documentary:

"All that legal stuff is new to me. Hearing stuff on television like violating law and sovereignty of states. Still strange to me, having to talk with a bunch of lawyers to coordinate my next moves. [...] Judging the age group and gender of people. All new stuff with big implications." (Interview 24)

Workers have also become aware of other external discourses; for example, when the South African cleric Desmond Tutu criticized America's “moral standards” for launching drone strikes. 
In sum, for the workers the drone-led changes have led to discontinuity in their core meaning, and values, which no longer serve as reference points in their relationship to their work.

\section{Emotional ambivalence arising from conflicting identifications with meaning, and values}

Following these changes to core meaning, and values, workers frequently reported contradictions in how they identified with their work. They had difficulty identifying with their new role of "drone warriors" for "the Chair Force [instead of Air Force]" (Interview 21). In the words of one interviewee:

"This [drone program] is like an earthquake; it's torn down our fundaments and now all is upside down. Stripped the pilot from the airplane in the sky and put pilots on the ground in front of a monitor, pretending to fly the thing. [...] It raises so many questions from how I see the military, the goals and purpose of our missions [...] I am doing here. [...]." (Interview 10)

Workers found it hard to relate to this new normal. This was reflected in statements such as "I am no longer sure who I am in relation to the USAF" (Diary 11) or "These changes left me asking who the heck am I" (Diary 29). The drone program was described as taking the essence out of "being a soldier." One worker described how the introduction of drones had "brought good and bad," with some aspects making him want to weep while others made him want to celebrate, with the result that" ultimately I just feel torn". Workers thus experienced conflicting emotions about their work.

Positive identification. Despite the severity of the changes and the disruption to values and meaning, most workers stood by the military doctrine, regarding it as being part of the Air Force. For example, during a calm moment on a field visit, one pilot reflected on the importance of their training as a key point of identification, including the values and meaning and what mission success meant to him:

"Above all I am soldier, and the biggest goal is to have the six of my colleagues and bring everyone back home [...]. We get into big trouble if an RPA crashes or, God forbid, it's taken down by the enemy but between us, I don't mind so much. If a UAV goes down, we lose money, but if an actual plane goes down, we lose one of our own. [...] Now everybody can serve [in the USAF] and it is not at all about bravery and sacrifice like before." (Field note 91)

Similarly, other workers saw this new technology as being in keeping with their work values, declaring that, given the (partial) withdrawal of American troops from war zones, "We won't lose any friends anymore if we use RPAs," and there will be "no more funerals to go to." They also stressed how the technology was in line with their overall mission: 
"We take pride in operating it [the drone technology] as the most powerful country. We are capable of protecting our ground troops stationed in foreign territory and in situations like no other nations are. With this technology, we are able to gain the upper hand against any insurgents." (Interview 11)

Enabled by the new work schedules, workers pointed out that the changes allowed them to be "in two places at once" and had positive effects on the "soldier's work-life balance" (Interview 11). For example, workers welcomed the change to have a "9 to 5" job as it "finally allowed a normal family life, being a present father and not missing school recitals" (Diary 31) and provided a "good chance not to tank this marriage like the one before, where I was more gone [military assignments overseas] than married" (Interview 22). One worker described this even more cynically:

'USAF has finally updated the work conditions to meet family life standards and broke that cycle to co-sponsor the entirety of divorce lawyers state-side." (Interview 05)

Negative identification. At the same time, working for the drone program was also seen by many as "career suicide," a "dead-end job," or a "de facto demotion." While being a fighter pilot is an esteemed professional identity, popularized in movies like Top Gun, being a drone pilot is regarded as an emasculated role, requiring no bravery or physical endurance, and is often seen as a second-rate military career (Internal document 236). Many regretted not seeing themselves as soldiers anymore, given their "lack of skin in the game," and lamented getting much less respect than colleagues "who actually travel to the front line."

"After Iraq, I got a medal for my service, even a bonus...we got treated like stars, like celebrities. [...]. The lady in the local hair shop gave me a free haircut. Now after working 12 months [for drone program], people [don't care] about my service [any longer]...People seem to think just because I sit in front of a computer, I don't do anything dangerous [...] but they don't know that I have killed more people here [in the U.S.] and seen and watched dying, than during my whole tour in Iraq." (Diary 13)

As the traditional boundaries between the home and the battlefield dissolved, workers began to question their fit to the values of their work:

"The military was a guiding principle before, and I was very excited to be part of this force protecting our country. There was always a very good fit between me as a person, as a soldier, and the AF. You could also say, we were one person. [...]. Now with the UAV stuff, I started to very much raise this question if this still holds true. [...] Stuff like 'leave no one behind,' which was the value, now doesn't apply, and many things are just not the same. Next to me sits a 20 -year-old who looks like he's doing competitive eating. There is zero discipline if you ask me." (Interview 17)

Overall, it was not only experienced personnel who questioned their fit to the organization, experiencing both negative and positive identification. Even recent recruits without on-the-ground experience 
in foreign territory struggled to identify with the "degraded" nature of the work. They described how the experience did not match their image of the military. A drone operator who had joined recently noted this:

"Yeah, sure, I don't know the past. But one buys into the whole military story. I got hired into this ship as they are the ones protecting America. It was always important to me because I am into the value of what our military stands for. Protect us from the enemy but it [the UAV program] makes it very difficult for one. I feel like a second-tier soldier if a soldier at all. If I do good, I can get the Nintendo medal, as it's called in the media, but nothing else, as my work has no valor or risk to life." (Interview 41)

Conflicting identifications evoke emotional ambivalence. Workers experienced "conflicted feelings"

in relation to the changes brought about by the UAV program and their implications; these feelings ranged from anger, embarrassment, and guilt to pride, satisfaction, and sympathy. Many workers told us how they felt a sense of pride and excitement now being closer "to action" and were positive about the improved situational awareness and the advantage the technology offered in fighting the war on terror. In a heavily redacted doctoral thesis, an Air Force lieutenant noted that:

“...they [mission commanders] saw more battles, saved more lives, and killed more insurgents than their airborne peers, and they cherished the relationships they developed with supported ground forces." (Cullen 2011: 200)

At the same time, as indicated previously, workers often felt moral anguish arising from observing

and monitoring people they knew were living their last moments (Diary 22). One diarist (pilot) reflected:

"[...] seeing a human being in their last seconds before it all ends, especially if it's a child, is just cruel. And then we hover above to see if they are still moving, or running away, if we can PID or we were wrong again in sending down another hellfire missile. [...] My heart goes BOOM BOOM. Difficult to put in words the feeling when releasing the trigger, because I know I could be doing something good and there is great joy about it but also if we got it wrong, there's great horror and sadness that I can't get out of my body." (Diary 33)

Despite being excited about being closer to their family and "having a chance for civilian life" (Diary

40), workers described the context-switching between the military and civilian life as emotionally taxing, especially when "an op [operation] went sideways" (Diary 20). One operator noted that:

"I have now a chance to really live a civilian life and take part in it. At the same time, it is really disturbing, going directly from war to your in-laws. [...] Often, I take anger or a sense of guilt and embarrassment to my house. [...] This feeling is there when things get messed up but also because of the absence of 'an eye for an eye.' We sneak up on them and, boom, party is over." (Field note 32)

These extraordinary demands on service personnel are evident from a rare, publicly disclosed incident that went wrong in Uruzgan province in Afghanistan. In February 2010, three vehicles traveling in a group 
were spotted by a drone. While this drone operation played out over hours, the eventual decision to fire three hellfire missiles on the vehicles resulted in the death of 23 innocent civilians and injuries to 12 others, including five children, aged six to fifteen, and one female (official report by the U.S. Army Deputy Commander, General McHale). Following the standard procedure, the drone crew continued its surveillance to assess the situation and engage in further actions if needed (e.g., firing again on squirters). However, shortly after the three missiles were launched, the crew spotted "three individuals in a brighter dress garb, supposedly females" and children. Due to this shift in events, the sensor operator who had previously stated “more dudes, more chances" (USAF Centcom 2059-2062-001982) now said, one and a half hours later:

"Yeah, at this point I wouldn't... I personally wouldn't be comfortable shooting at these people."

These excerpts show not only the opacity and "blurriness" of their rules of engagement and of the definitions of a legitimate target but also the dire situation these operators were in, when they knew that "one was involved in getting innocent people killed" (Diary 20). In such instances, workers frequently vented their frustration, outrage, and anger in their diaries, often questioning the moral and legal foundations of the missions but also expressing the anguish of having to switch back to civilian life "within a 20 -minute drive door-to-door" (Interview 12). Some indicated that the inconsistent criteria being applied to approve drone attacks was shameful, as reflected in this diary entry:

"Very ashamed we define any male above 12 as a combatant. This cannot be legal. If so, half of the US is a military aged male." (Diary 21 )

At the same time, an operator expressed a sense of pride during a conversation with us:

"There is no better feeling and moment of pride, when you go down and send some missiles to protect your own troops because insurgents [...] put them in a rough spot. And then you are able to get in with a precise strike and eliminate them. And boom, end of convo. This is for Stars and Stripes!" (Informal conversation 92)

Even though workers appreciated the fact that they could be safe and close to their family at home and could at the same time make life safer for their ground troops, their country, and even the world at large, their continued engagement in the drone program led to soul searching as they looked for ways to "find peace." They struggled with the changed meaning, and values of their job and with not "knowing if this is good or 
bad what I am doing." One drone pilot said, "There was a void that I felt which I had to fill, and the organization wasn't willing or didn't have the ability to fill it" (Interview 19). Another operator wrote:

"It is inevitable to ask the question would I be able to kill this person also face to face. Or am I ok taking somebody's life in cold blood without a chance to run away, fair trial and share his version of the story?" (Diary 26)

To varying degrees, all workers questioned the core meaning, and values of their work. While some cited a particular pivotal event (e.g., a major strike that went wrong), others described a longer process, referring to "weeks that I had this question in mind of where I actually stand" (Interview 22) and "goingback-and forth between my conscience and the sheer fact we live in a brutal world" (Diary 20).

\section{Workers' strategies for coping with emotional ambivalence about their work}

We identified four different strategies used by service personnel to address the contradictions in how they identified with their new work and to cope with the emotional ambivalence that these contradictions evoked: (1) Unconditional re-identification, (2) Reconciled identification, (3) Sidestepping identification, and (4) Estrangement. Appeals for help to those higher up the military hierarchy fell on deaf ears in an organization with a strong chain of command, and discipline. Such requests were "quickly muted and there was no interest from any side to provide help" (Interview 05). Our respondents confessed that emotions or mental health issues were a taboo topic that "does not belong in the military." They were told to "man up" as "a soldier never shows any weakness" (Diary 23). They were thus required to figure it out on their own.

Unconditional re-identification. The first strategy was to simply disregard the problematic aspects of the new technology by upholding the sanctity of the military values. Falling back on entrenched values and ignoring troubling emotions was a strategy employed by one group of workers ( 20 individuals); they resorted to the core values of being a soldier and of holding fast to the overarching purpose of safeguarding the country against evil forces. These individuals had strong roots in the military community. They coped by reminding themselves that choosing to become a soldier was a decision for life.' Those in this group often made statements such as "All in, all the time" and "My purpose is to serve, whatever demands come to me." A drone operator emphasized the importance of the sanctity of the chain of command: 
"Where will we land if we question each and every step of the chain? This is how it ran over hundreds of years. We have to trust the system, although this sometimes is of course not so easy when you are paid to watch children die [...].” (Interview 13)

Others expressed similar sentiments, citing the sanctity of the military ideology, the chain of command, and the higher-order military doctrine, which helped them to overcome the ambivalence they experienced:

“After months of grappling with myself, I decided it's not my job to question authority or motives. I follow orders as they have more information at hand to make an informed decision." (Diary 08)

This strategy was about upholding the ethos of the profession. One individual told us:

"To be frank, I have thought about leaving because this UAV stuff is a whole new ball game and tough shit, but in the end, I am a trained soldier. I belong to the military and serve my country. It is not my job to decide this or that. I am here to get the shit done. Follow orders and protect the United States of America and ensure that our children can go safely to school tomorrow." (Informal talk 13)

One individual with vast military experience noted that this "change was different than previous changes" (Diary 10). However, another operator noted that the UAV program "still has the same goals:"

"What we do here isn't that new or worth a big outcry by the media. Our purpose is the same. We protect the United States of America. We have used missiles and bombs as part of our strategy for many decades. It's just a different technology that does it now. Civilians are affected in every war. This goes back to when mankind was created by God. [...] It is just a different tool to protect our country." (Interview 7)

This strategy of falling back on existing values was different from constructing new meanings, as the members of this group did not try to justify the contentious use of drones. They argued that the goals of drone warfare were no different to those of conventional warfare: namely to weaken or destroy the enemy. They reminded themselves of the need for impassive emotional control or, in their words, to "ignore and overwrite," as had been inculcated in them during their training.

Reconciled identification. This strategy was employed by 17 of the workers we studied. These workers coped by looking for meaning outside their narrow mission and reframed the new work as meaningful and legitimate. They chose to regard the change in their work in a positive or righteous light and as a "force for good." One person said "there are just certain rules of the game that cannot be changed. So, it is our task to seek meaning again in our work" (Interview 22). Another operator stated:

"I shifted my own understanding of what I am doing here. If you ask me, I am OK with killing Tali [Taliban]. Yes, I [...] struggle when we get children. But yes, I am OK if somebody dies by accident if they are in proximity of an insurgent. I mean, would you hang out with a drug dealer, Nazi, or 
murderer? I actually don't see myself anymore as a soldier for the USA but for the world [emphasis added]. We need to clean the world and remove all those [...] threatening the Western world and freedom. Not everyone needs to believe in Islam." (Field note 28)

Other experienced personnel described how drones were a technological advancement that enabled them to be "more precise," pointing out that "now we can click and select who they want to target" (Interview 25) and cause less collateral damage than with aerial bombing. Another person stated that:

"We can be more efficient now. We have moved to being a surveillance company and have amazing situational awareness now. We can protect the good local people like Tik, Trik, and Trak [cartooninspired nicknames that the operator liked to check on]. And we can precisely target [those] that need to be removed from the world, because we can really see now their movements 24/7." (Interview 29)

Members of this group came to appreciate how technology had changed the face of war. One diarist noted:

"We have to go with the time and be OK with moving away from the thrill seeking face to face with the enemy. This new technology allows us to bomb [...] from a safe distance without putting any of our boys in harm's way. This is the way to go forward." (Diary 31)

Other individuals found meaning in "knowing" that U.S. soldiers would no longer be affected by the "cruelties of war" (Interview 10) as "UAV technology helps in no more pall-bearing as we can get the job done from home" (Diary 25). One diarist wrote:

"I [...] regret the Iraq invasion. [...] I lost so many brothers on the battlefield. [...] RPA war is [messed] up too, we get wrong people and there is no end to it. [...] After end of each shift I touch the wobble head of Brian [fallen soldier on a joint mission] and know again why I am [...] doing this pressingbutton-war. For him! [...] We'll continue this war forever. There is no end mission goal. [...] I... don't believe in this shit anymore but [do it] for my [fallen] brothers." (Diary 26)

Those who drew on this strategy moved from mission-specific goals to private motivations, such as doing it "in the name of my fallen brothers," "helping little girls go to school," or "making the world a better place." This strategy was different from falling back on established values as these workers were not simply reminding themselves of the military ethos but were rather extending the meaning of their work.

Sidestepping identification. Focusing on the "job at hand" and "not getting too caught up in it" was the third type of response strategy. Those using this strategy ( 7 individuals) sought to ignore their concerns about the deeper meaning of work. They "accepted things" as part of their job. They focused on the "money," treating their work as a "job to make ends meet" and not as a higher purpose or calling to protect their country:

"I don't want to get involved in the politics of all of this. For me it is just a job. Stuff that others seems to care about, that we walk around in (Air Force pilot) overalls, I don't care much about that. I mean, 
it's good they give me work clothes and I don't need to bother with buying clothing just for work, right? Yes, I often have to swallow down [stuff] but I just stick to the routines and do what is required of me. I try not to think much and just do my work." (Informal conversation 21)

Similarly, a diarist wrote that:

"I have no influence to make this a better place of work. I go in, do my shit, and remind myself of the check at the end of the week. After all, work is paid well for sitting around." (Diary 40)

The majority of those in this group had relatively little experience in the military, did not come from military families, and were not deeply rooted in the military community. Instead, some were recruits from gaming conventions, and the UAV program was their first experience of the military. One person told us:

"I am not attached to the whole military thing. I got inside because I saw the ad and it is good money. I am a school dropout and there is not much available where you can make easy money and don't work your body to death." (Interview 37)

One worker in this group shared his sentiments about why many struggled with the work:

"People in the AF take themselves and the AF too seriously. [...] The money is good, and if I don't like it anymore, I can go somewhere else. Maybe drive for Uber or other stuff. People speak about ethics and moral and stuff but, hey, look it is better than selling a burger to fat people at Mickey D [McDonald's]? One shouldn't do it, but they keep on doing it, despite knowing it ain't good. It is slow death. I have health insurance here and some other pretty good benefits. I am pretty OK with it." (Informal conversation 56)

This strategy of focusing on the task at hand was different from falling back on established values (unconditional re-identification), even though many tried to suppress their emotions. However, they did so not because of the soldiers' imperative to "ignore and override"; instead, they used emotional control as a protection mechanism to survive in the job and reap its perks, including free healthcare.

Estrangement. Finally, when none of the first three strategies seemed viable, workers severed their ties and left the organization. This last strategy was based on a refusal to compromise. In total, 14 individuals decided to leave the organization. Four of these had previously been in the "fall back on entrenched values" group (unconditional re-identification), four in the "create new meaning" group (reconciled identification), and six in the "avoid meaning" group (sidestepping identification). Interestingly, only one of the recent recruits, a technician, remained in the organization. He was tasked with aircraft maintenance, not with flying operations or surveillance, and when prompted, he said: 
"Mainly I fix small bugs in the reaper. I don't have anything to do with what goes on in these boxes [where the cockpits are located]. I actually like my work because it is similar to the model airplanes, well bigger, that I have at home." (Interview 40)

Individuals stated that they could "no longer emotionally control and avoid their actual feeling of disappointment in the military system and what we are actually engaging in" (Interview 22). Some became disillusioned, despite their good standing in the military community. One decided that the "only option was to leave the Air Force" and declared that "now war has no finish line" (Diary 20). Another noted that "War has a grip around your soul, and I needed to get away from watching people die on a screen" (Diary 2). Members of this group "saw no other alternative than leaving." Others cited the loss of the moral values of work as the reason for leaving the Air Force (Diary 27). One diarist noted:

“I can't handle the fact that people are killed because of our [mistakes], and then we send our lawyers in with mourning money and we have to make sure they [providing consolation money] are not being killed by locals. And then we have the [...] guts to give the same amount for a loss of life and a destroyed car [for example, in a hellfire attack, a reference to an incident in 2010, where those who had lost family members in a hellfire attack were paid $\$ 5,000$ for the loss of a family member and $\$ 5000$ for a destroyed car]. How to explain this to any taxpayer? We kill them only to then give them money for killing [them].” (Diary 13)

Workers reported they could not "reconcile" themselves to such difficult experiences and felt disturbed about being involved in something that went against their "understanding of what fair means" (Interview 22). They had issues with the secrecy around people on their "target list" and with not knowing "who and how [someone] ends up on my desk" (Diary 02). With many missions being "kill" missions, they felt uneasy with the idea that targets had no chance of defending themselves, nor any recourse to the law.

"They have no chance to present their case and defense. How do I know that this is actually an insurgent and the stuff in his truck under the sheet isn't stuff for the harvest in his backyard and not to blow someone up? Just cause [he] wears a greyish kameez shalwar [traditional male clothing in parts of Afghanistan and Pakistan] like everybody else? [...] This blind trust that I had before for the AF I don't have any more since UAV is in town." (Diary 04)

Working in the drone program had severe effects on many personnel, leading to sleep deprivation, post-traumatic stress disorder, and drug abuse. In particular, those who had "focused on the paycheck" could not continue, having soon realized "that the money isn't worth it for watching people die" (Diary 41). One individual who had previously advocated focusing on the above-average paychecks said:

"Half of my salary I invest in all sorts of stuff to sleep, get me drunk, and my usual steady supply of Xanax. But the majority of times I am too low to go out after a shift." (Interview 37) 
Many cited "wanting to forget" and "peace of mind" as reasons for leaving. A former drone operator stated:

"I needed to save myself. I couldn't go on working for this assassination program any longer. And at least I know that, if I go, they will be at least one man short to already being under capacity, which means at least for some minutes fewer killings will happen until they can recruit some naïve high schoolers with a gaming addiction." (Interview 23)

In summary, we identified how people used different response strategies to handle the emotional ambivalence they experienced. By drawing on these strategies at different points in time, individuals attempted to cope with that emotional ambivalence and to establish what they called a "moral peace."

\section{A Model of Technology-Induced Emotional Ambivalence and Coping at Work}

Using multiple data sources, including the personal diaries of active service personnel, we have developed a model of how an emerging technology changes the meaning, and values of work and how workers respond to such disruption to their work that they identify with strongly (Figure 1).

\section{---Insert Figure 1 here---}

Our model captures how an emerging technology can prompt changes in the core meaning, and values (arrow I). Drone technology, with its remote piloting of unmanned vehicles, remote-split operations, and interaction through iconic representations, brought changes in the core meaning, and values, which no longer served to guide the behavior of workers (arrow I). The technology created a change in core meaning, and values of work and (1) created distanciated intimacy, (2) disrupted traditionally conceived spatio-temporal boundaries, and (3) changed the moral and legal parameters of work.

However, different organizational workers might react differently to a change in work depending on (inter alia) their experience with the organization and level of commitment to it. Workers may identify in conflicting ways with the new meanings, and values of work (Elsbach 1999), which elicits emotional ambivalence (arrow II). In our case, workers identified both positively and negatively with the new values of drone warfare (e.g., waging war through remote control and being able to kill with impunity), and this made them feel conflicting emotions about the notion of right and wrong (arrow III). Indeed, it is well-established that it is possible for individuals to "experience positive and negative emotions" about an "object, event, or idea" at the same time (Fong 2003: 2; Pratt 2000; Pratt and Doucet 2000). In an organization with a closed culture and strong feeling rules, and where senior leadership provides little guidance on how to manage 
feelings, individuals may deploy different strategies to cope. The first strategy we identified, unconditional re-identification, is for workers to disregard the ambivalence they feel about their work and to hold fast to the sanctity of their organizational mission. Here they tend to "ignore and override" doubts (Kahn 2019) and abide by the ethos of their profession. They create an "emotional distance" (Pratt and Doucet 2000) to buffer themselves from any negative feelings towards the change. By dismissing the negative side of "ambi" valence, they turn ambivalence into positive univalence (arrow IV). Such behavior was described by Coser (1979) as the denial or evasion of ambivalence. In our case, the experienced personnel who adopted this strategy fell back on their military socialization and on the rule that they should "not ask questions," and should remain unswervingly loyal (cf., Hirschman 1970).

With our second strategy, reconciled identification, individuals initially experience a void in what it means to be professional worker. They then attempt to reconstruct new meaning around the new values of their work and recast the negative valence (arrow V) to restore a positive sense of self once their work appears to have become "dirty" or tainted (Ashforth et al. 2007). They may feel ambivalent about their work but are nonetheless able to focus on positive aspects of it. In our case, service members focused on how drones brought stability and peace to the region and saved lives; they regarded them as being no worse than conventional weapons and saw them as even having some advantages.

With regard to the third strategy, sidestepping identification, individuals look for meaning not in the work itself but in the personal benefits they derive from it. They compartmentalize their emotions by focusing on the tasks at hand, circumventing identity concerns (arrow VI) and not dwelling on the deeper personal meaning of their work (Alvesson and Robertson 2016). In our case, new recruits who had been lured by the "dream" of being part of the military focused on the perks of the job, such as being able to get above-average pay without a college degree. While this approach is similar to the strategy of reconciling identification, those who adopted this strategy began to view their work as simply a "job," rather than a higher calling.

With the final strategy, estrangement, those who simply cannot cope with the new way of working sever their ties and leave the organization. Such a strategy is considered to be the last resort when all other strategies have proven inadequate for coping with the emotional conflict of working for the organization 
(arrow VII), and workers decide to leave (cf. Hirschman 1970). In our case, only a few experienced workers, but almost all the new workers, left the military. New members may initially be able to bypass identity concerns by focusing on the more immediate benefits of the job, but they may still find it hard to maintain that approach if they find the work morally troubling. In addition, they may face fewer exit barriers than those with more experience who feel a greater commitment to the profession.

\section{DISCUSSION}

Our findings allow us to make three main contributions to the literature on technologies and work.

\section{Emotional responses to remote technologies}

First, we show how remote technologies evoke emotional responses in workers by disrupting the core meaning and values of their work. Studies on technologies and work have explained how technologies can reconfigure roles and relationships and disrupt status hierarchies, leading to different responses from workers (Barley 1990; 2015; Barrett et al. 2012). We extend these studies by showing how people respond emotionally to a remote technology based on the values that tether them to their work rather than on disruptions to their

role, power, or status, and how strong emotions are evoked when these values are violated by the technology. These emotions are likely to be particularly strong when people working in ideology-driven organizations consider their work to be a calling and regard their professional values as sacred. We contribute to studies on technologies and work by exploring how meaning, morality, and feelings play a part in workers' responses when emerging technologies disrupt the meaning and values that have traditionally underpinned their work.

Studies of technologies and work have examined how technologies evoke emotions such as awe and excitement or stress, anguish, and insecurity stemming from a lack of trust in the technology (Bailey et al. 2012; Beaudry and Pinsonneault 2010). For example, in situations that involve remote control, workers may distrust or place a great deal of trust in the iconic representations of remotely located artefacts that they no longer have haptic or direct physical control over (Zuboff 1988). These studies have shown how trust and distrust of a technology evoke emotions (e.g., Hirschhorn 1984; Perrow 1983), but they do not focus on the emotions that may arise from doubts about the morality of the technology. In contrast, we explain the role of moral emotions pertaining to feelings of right and wrong in shaping workers' responses. For example, 
workers may form moral judgements about the technology; some of them may see drones as allowing a "humane war" to be conducted, whereas others may see them as enabling unsuspecting targets to be killed with impunity, targets whom they are watching at the very end of their lives. Such moral judgements evoke feelings of both satisfaction and guilt, and workers deploy a mix of strategies to come to terms with the ambivalence they experience about their work. While social media is not a remote technology, it can also evoke moral emotions; people may feel a sense of solidarity if they receive social support from other users, while those who feel they have been unfairly targeted, misled, or harassed may feel anger and resentment.

Also, workers may feel morally responsible for technology errors, biases, and accidents. In our case, service members felt emotionally distressed and saw themselves as morally culpable for the life-and-death decisions, rather than blaming the technology. We did not observe any denials of responsibility to reduce negative feelings that arose from the violation of their own values. Moreover, being engaged in secretive drone programs, seen by many as "dishonorable" compared with in-person operations, evoked feelings of anguish and despair in the drone operators because they felt that the profession they held dear was being morally degraded. This once again showed the emotional side of workers' responses to new technologies. Another example is the "selling out" of software licenses at MIT, which violated the moral values of local software developers, and sowed the seeds of the open-source software movement (von Krogh et al. 2012).

Previous studies on values and work have focused on settings that involve prosocial work such as nursing (Bunderson and Thompson 2009; Schabram and Maitlis 2017); we complement those studies by shedding light on the emotional challenges people face in non-prosocial settings and on how technologies disrupt the values on which their work has been based. We show how such disruption evokes emotional ambivalence as people identify both positively and negatively with their new work. Our findings suggest that leaving an organization is a distinct possibility when workers are unable or unwilling to cope with their conflicting feelings and to come to terms with the change. Also, while the meaning and values of work are constructed collectively by workers, we show how they can also be crafted individually. Our findings suggest that values can be both a source of meaning that workers draw on in their work and an outcome of the meanings they construct with regard to their work. 


\section{Characteristics and Outcomes of Remote Control}

While remote control, or managing artefacts remotely through representations, has been given less attention in studies of technology and work (e.g., Bailey et al. 2012; Hirschhorn 1984; Perrow 1999), we identified specific characteristics: a remote split between operations; 2) remote piloting of objects, and 3) interaction through iconic representations. Such technology may lead to changes in "network-centric" operations, control, and manipulation of a complex system of digital artefacts, and a reliance on iconic representations not just of artefacts but also of human subjects in real time. Studies have shown that when workers manipulate physical objects remotely using digital interfaces, as in robotic surgery (Beane 2018; Beane and Orlikowski 2015), it changes the organization and coordination of work, and raises issues around workers' level of trust in the digital representations (Bailey et al. 2012; Perrow 1999; Zuboff 1988). In robotic surgery, doctors remotely control a surgical system - mechanical arms, surgical instruments and cameras to perform procedures on patients in collaboration with nurses, anesthesiologists and other staff on site. Similarly, scientists and engineers involved in "The Mars Exploration Rover" mission work with "robotic teammates millions of miles away" (Vertesi 2014: 7) to study the Martian surface. Such work has been described as "a highly visual experience" that "suffuses the team members' interactions with the robots and with each other" (Vertesi 2014: 6). Our study adds value by explaining that when people interact with objects and human subjects remotely, they may struggle to realize the values that they attach to their work. They may then experience not just a loss of trust but also a challenge to what they feel to be morally right or wrong.

We also identified three main changes that remote control can bring to the meaning, and values of work: 1) distanciated intimacy, 2) the dissolution of traditional spatial and temporal boundaries, and 3) changes to the moral and legal parameters of work.

Distanciated intimacy: Remote control can have the paradoxical effect of creating both distance and proximity with regard to the objects or targets being controlled, as it places "analytical distance between the operators and the objects" (Bailey et al. 2012: 1488). For example, technologies that provide panoptic surveillance of employees from a distance allow managers to violate the employees' privacy by keeping them constantly under watch. In our case, drones made possible prolonged observation of graphic brutality, which 
became more unbearable for the observers when things went wrong and there were unintended casualties. In conventional field warfare, where workers have haptic or manual control of the aircraft, service personnel were accustomed to attacking and killing targets, but unlike the drone pilots they did not get to observe their targets and their plight so graphically. Watching, in vivid detail, brutal scenes that involve someone they had observed closely evoked strong emotions in the drone operators. Indeed, graphic images can evoke powerful emotions even when what they depict may be an established fact. For example, the plight of refugees during the 2015 European immigration crisis was no secret, yet the shocking image of a migrant child lying dead on a beach in Turkey crisis stirred strong emotions in those in government and in refugee organizations, and also in members of the public, leading to a stronger response (Klein and Amis 2020).

Similarly, while traditional surveillance via CCTV technology is by no means a new phenomenon, the way in which it is used today provides ubiquitous electronic eyes and allows constant monitoring of homes, offices, and schools from a network of indoor and outdoor cameras and sensors. This allows distanciated intimacy; the ability to not just watch real-time video and observe people's behaviors in graphic detail from anywhere but also to track behaviors. While such centralized surveillance devices in a world of "surveillance capitalism" (Zuboff 2019) can promote security, they are also morally contentious. For instance, they are vulnerable to hacking, allowing strangers to gain detailed access to people's private lives. Also, while not a remote technology, "zoom" based virtual teaching from home creates a sense of both distance as teachers talk to students on screens, and intimacy; those taking part get a glimpse into the private lives of each other (with children and pets sometimes making an appearance in zoom calls).

Dissolution of traditional spatial and temporal boundaries: Remote work has changed the traditional work relationships and dissolved the separation between work and home, and between personal and professional life. While prior work has addressed the blurring of boundaries between work and home through new technologies (e.g., Ashforth, Kreiner and Fugate 2000; Weick 1979; Zerubavel 1991), we depart from this research by showing how remote technologies can dissolve the separation between working in demanding contexts (e.g., a warzone or the site of a fire) and being in a safe place. At the same time, they also dissolve temporal boundaries as the work expands in scope and duration. In our case, military personnel 
were used to a strict separation between work and home. They were used to fighting in war zones and returning home as war "heroes." Drones dissolved this separation as people "fought" battles from remote cubicles and returned home the same day. Similarly, from a temporal standpoint, drone operators are perpetually "at war somewhere at any moment" in what has been described as an "endless war" with no "finish line." Even the official end of a war (e.g., the withdrawal of U.S. troops from Afghanistan in 2021) does not mean the end of remotely conducted drone warfare in that country or region. The growing use of remote control enabled by a global network that allows round-the-clock surveillance has expanded the scope of war and made it perpetual in time. The technology makes it possible to stretch war further and further, or in other words to wage war in any part of the world at any time.

We have seen how email and social media create an "always on" culture, giving workers flexibility but also dissolving the traditional separation between work and home or between being on duty and off duty. Such technologies can "steal" time and space; they allow workers to be productive outside traditional office hours and to work outside the formal office, meaning that their work can be extended in dimensions of both time and space. Such stretching of temporal and spatial boundaries means that aspects of people's family or recreational life, or other non-work areas, spill over into their work life, and vice versa (Mazmanian 2013; Nurmi and Hinds 2020). This can make it difficult for them to carry out their roles adequately, especially when the demands of these roles conflict.

Disruption to the moral and legal parameters of work: Finally, remote control can change the moral and legal parameters of work. The use of drones by a state transgresses the established rules of engagement in conventional war as it enables military intervention in sovereign countries even without their permission. In drone war, the U.S. government has set new definitions of what can be regarded as a legitimate target (e.g., a 12-year-old male) or a war zone (e.g., a place of private residence). Another example is the remote control and intelligent guidance systems used in autonomous vehicles such as driverless cars, and the questions these raise about who should take the blame or be held morally responsible when things go wrong. Discussions about the difficulty of allocating moral responsibility when using remote control technology indicate there is a "responsibility gap" (Hansson 2018: 1822-24). Programming vehicles to make the kinds of nuanced, 
situated decisions that drivers must often make on the spot to avoid accidents is morally complex. Emotions are clearly at play when we see higher moral outrage from regulators and the public in the case of fatal accidents that involve arguably "safer" autonomous vehicles (e.g., such as those developed by Tesla or Uber), even though human drivers are involved in over a million road fatalities per year.

Consider, for example, how the use of AI in police work may not only devalue the professional judgement of police officers and undermine public trust (Brayne 2017) but also raise moral and legal questions, in that it may reinforce existing social biases. More data is generated on people from disadvantaged backgrounds, who use public services more frequently. This makes them more likely to be flagged as a risk. Using existing police records to train machine-learning tools introduces a human bias by inscribing the arresting officers' own prejudices into the datasets.

Finally, in the digital age, as users leave a growing digital trail or "digital exhaust," they become "data representations" whose behaviors can then be predicted and manipulated both overtly and covertly through AI (Leonardi 2021). Such manipulation can be a threat to fairness and equity in the workplace, as employees may be unfairly advantaged or disadvantaged by being constantly monitored and manipulated into desirable behaviors (Leonardi and Treem 2020). With a growing share of our interactions taking place in the digital realm, not only do these technologies change the way work is organized but they also raise legal and moral issues regarding people's right to privacy in an information society. This was aptly captured in the 2020 Netflix documentary, The Social Dilemma, which deals with the vulnerability of teenagers who use social media platforms such as Instagram and have allegedly suffered rising levels of depression and anxiety. Privacy is also about accountability, and there is arguably a moral obligation on business and governments to defend and affirm people's right to privacy when emerging technologies invade private spaces and are used to influence behaviors in subtle and imperceptible ways.

\section{A novel methodology for capturing emotions evoked by an emerging technology}

Finally, our access to diaries allowed us to capture emotions that people feel when technologies disrupt the meaning and values of their work but that they may not be able to display. In organizations with masculine cultures (O’Neill and Rothbard 2017) or those that lack psychological safety (Edmondson 1999), individuals 
cannot talk openly about difficult experiences for fear of reprisals, and they have little organizational support to alleviate the emotional distress that they might experience (Kahn 2019). In such cases, it is hard to capture such emotions through traditional methodologies such as interviews or observation of those individuals' behaviors (de Rond and Lok 2016) or from decoding non-verbal cues (Sanchez-Burks and Huy 2009).

Diaries are created by individuals to keep a regular, personal, and contemporaneous record of their experiences. While diaries have been neglected in organizational studies (Rauch and Ansari 2021), diary writing has also been shown to have demonstrable psychological benefits (Amabile and Cramer 2011). As a complement to data from observation, interviews, and archives, diaries strengthen the existing methodological arsenal, enabling researchers to capture "thoughts, feelings, considerations, and reactions" (Radcliffe 2017: 190) at the point at which they are felt, without the bias of retrospect or socially desirable responses. Data from diaries shed light on people's emotions that cannot be gleaned from their observable behaviors. In our case, the feelings of the military service members we studied could not be discerned from the behaviors they exhibited in the workplace. Our study highlights the need for organizations to provide ways in which people can share their emotional burden and to foster a more supportive culture in which difficult feelings can be expressed.

\section{LIMITATIONS AND FUTURE RESEARCH AVENUES}

Our study has several limitations, which also suggest avenues for future research. First, to protect the anonymity of our diarists, we refrained from probing into areas that would reveal their identities. Future research could examine how particular traits (e.g., tolerance of ambivalence) help people to cope with mixed emotions. Also, we did not consider how the technology had been designed (e.g., drone cubicles on the ground closely resembled the cockpit of a fighter jet, which places certain constraints on remote piloting). In our setting, bad weather conditions such as thick cloud made the iconic representations fuzzy and sometimes led to deadly errors. Also, during "takeoff," drone operators were only able to look at the ground below instead of getting a panoramic view - a crucial feature for takeoff and landing maneuvers - and, as one interviewee noted, they could not "simply look out of the window, turn my head and use the 365-degree function of my head as on a B-1" (a conventional U.S. Air Force bomber) (Interview 11). This suggests the need to consider 
the social and ethical implications of the design of a technology long before it enters the workplace, especially with intelligent technologies that have disruptive potential (e.g., Bailey and Barley 2020). In addition, it would be useful to look more closely at cognitive and emotional trust in the technology, especially when the drone program will be further "unmanned" through the use of AI (Glikson and Woolley 2020). Also, while there are limits to what one can extrapolate from a single case, other studies could examine how the recruitment of atypical workers may transform the overall profession. Finally, our findings have implications for how organizations can enable their workers to voice their feelings freely, especially remote workers who have no recourse to the safe and secure "holding environment" (Petriglieri et al. 2019) within an organization.

\section{CONCLUSION}

Emerging technologies are increasingly reshaping human action and interaction across a wide variety of domains, transforming how we work and live (Bailey and Barley 2020; von Krogh 2020). We suggest that workers' responses to these technologies are based not just on how these changes disrupt the way work is organized, transform roles, or disrupt power hierarchies in the workplace. Rather, they are centered also on the workers' own feelings about the core meanings and moral values that tether them to their work. We have shown how workers experience and respond to remote control technologies (Bailey et al. 2012) that disrupt the meaning and moral values of their work and evoke emotional ambivalence. Drone technology has allowed distanciated intimacy by enabling warfare to be conducted remotely while also giving those involved a graphic picture of the potential targets of their drone strikes. It has also allowed war to be conducted "endlessly" and potentially anywhere on earth by stretching the spatio-temporal boundaries of war and redefining its moral and legal parameters. Workers struggled to identify with the new normal of work and deployed several strategies to come to terms with it. Our study shows that people do not necessarily value primarily the immediate benefits or rewards that new technologies can bring to their work but may instead be seeking a sense of meaningfulness and moral fulfillment. 


\section{REFERENCES}

Amabile T, Kramer S (2011) The Progress Principle: Using Small Wins to Ignite Joy, Engagement, and Creativity at Work. Harvard Business Review Press.

Alvesson M, Robertson M (2016) Money Matters: Teflonic Identity Maneuvering in the Investment Banking Sector. Organ. Stu. 37(1):7-34.

Ashforth BE, Kreiner GE, Fugate M. (2000) All in a Day's Work: Boundaries and Micro Role Transitions. Acad. Management Rev. 25(3):472-491.

Ashforth BE, Kreiner GE, Clark MA, Fugate M (2007) Normalizing dirty work: Managerial tactics for countering occupational taint. Acad. Management J. 50(1):149-174.

Bailey D, Barley S (2020) Beyond design and use: How scholars should study intelligent technologies. Inf. Organ. 30(2): 100286

Bailey DE, Leonardi PM, Barley SR (2012) The lure of the virtual. Organ. Sci. 23(5):1485-1504.

Baumeister RF, Vohs KD (2002) The pursuit of meaningfulness in life. Snyder CR, Lopez SJ, eds. Handbook of Positive Psychology (Oxford University Press, Oxford), 608-618.

Barley SR (1986) Technology as an Occasion for Structuring: Evidence from Observations of CT Scanners and the Social Order of Radiology Departments. Admin. Sci. Quart. 31(1):78-108.

Barley SR (1990) The alignment of technology and structure through roles and networks. Admin. Sci. Quart. 35:61-103.

Barley SR (2019) How Do Technologies Change Organizations? Work and Technological Change. Oxford University Press

Barley SR, Kunda G (2001) Bringing Work Back In. Organ. Sci. 12(1):76-95.

Barley SR, Bechky BA, Milliken FJ (2017) The changing nature of work: Careers, identities, and work lives in the 21st century. Acad. Management Dis. 3(2):111-115.

Barley SR, Meyerson DE, Grodal S (2011) E-mail as a source and symbol of stress. Organ. Sci. 22(4):887906.

Barrett M, Oborn E, Orlikowski WJ, Yates J (2012) Reconfiguring boundary relations: robotic innovations in pharmacy work. Organ. Sci. 23(5):1448-1466.

Beaudry A, Pinsonneault A (2010) The Other Side of Acceptance: Studying the Direct and Indirect Effects of Emotions on Information Technology Use. MIS Quarterly. 34(4):689-710.

Beane M (2018) Shadow Learning: Building Robotic Surgical Skill When Approved Means Fail. Admin. Sci. Quart. 64(1):87-123.

Beane M, Orlikowski WJ (2015) What Difference Does a Robot Make? The Material Enactment of Distributed Coordination. Org. Sci. 26(6):1553-1573. 
Bechky BA (2020) Evaluative Spillovers from Technological Occupational Practices in Forensic Science. Admin. Sci. Quart. 65(3):606-643.

Biernacki P, Waldorf D (1981) Snowball sampling: Problems and techniques of chain referral sampling. Sociological Methods \& Research. 10(2):141-163.

Boyle MJ (2015) The legal and ethical implications of drone warfare. Inter. Jour. of Human Rights. 19(2):105-126.

Brayne S (2017) Big data surveillance: The case of policing. Amer. Sociol. Rev. 82(5):977-1008.

Brusoni S, Vaccaro A (2017) Ethics, Technology and Organizational Innovation. J. Bus. Ethics.143:223226.

Bunderson J, Thompson J (2009) The Call of the Wild: Zookeepers, Callings, and the Double-edged Sword of Deeply Meaningful Work. Admin. Sci. Quart. 54(1):32-57.

Chell E (2004) Critical incident technique. In C. Cassell \& G. Symon (Eds.), Essential Guide to Qualitative Methods in Organizational Research (pp. 1515-1539). Sage.

Corbin J, Strauss A (1990) Grounded theory research: Procedures, canons, and evaluative criteria. Qual. Sociol. 13(1):3-21.

Coser RL (1979) Training in ambiguity: Learning through doing in a mental hospital. New York, NY: Free Press.

Cullen TM (2011) The MQ-9 Reaper remotely piloted aircraft : humans and machines in action. $\mathrm{PhD}$ thesis. MIT: URL:http://hdl.handle.net/1721.1/80249

Curchod C, Patriotta G, Cohen L, Neysen N (2020) Working for an Algorithm: Power Asymmetries and Agency in Online Work Settings. Admin. Sci. Quart. 65(3):644-676.

de Rond M, Lok J (2016) Some things can never be unseen: The role of context in psychological injury at war. Acad. Management J. 59(6):1965-1993.

Edmondson A (1999) Psychological safety and learning behavior in work teams. Admin. Sci. Quart. 44:50383.

Elish MC (2017) Remote Split: A History of US Drone Operations and the Distributed Labor of War. ST \& $H V / 42(6): 1100-1131$.

Elish MC (2018) 24/7: Drone Operations and the Distributed Work of Work. Columbia University

Elsbach K (1999) An expanded model of organizational identification. In R. I. Sutton \& B. M. Staw (Eds.), Research in organizational behavior, vol. 21: 163-200. Greenwich, CT: JAI Press.

Evans J (2021) How Professionals Construct Moral Authority: Expanding Boundaries of Expert Authority in Stem Cell Science. Admin. Sci. Quart. forthcoming

Faraj S, Pachidi S, Sayegh K (2018) Working and organizing in the age of the learning algorithm. Inf. Organ. 28(1):62-70. 
Fayard AL, Stigliani I, Bechky BA (2017) How nascent occupations construct a mandate: The case of service designers' ethos. Admin. Sci. Quart. 62(2): 270-303.

Foucault M (1982) Technologies of the self. lectures at University of Vermont Oct. 1982, in Technologies of the Self, 16-49. Univ. of Massachusetts Press.

Fong CT (2006) The effects of emotional ambivalence on creativity. Acad. Management J. 49(5):10161030.

Frankl V (1959) Man's search for meaning. London: Hodder \& Stoughton.

Freidson E (2001) Professionalism: The Third Logic. Chicago, IL The University of Chicago Press.

Friedland R (2018) Moving Institutional Logics Forward: Emotion and Meaningful Material Practice', Organ Stud. 39(4): 515-542.

Glaser BG, Strauss AL (1967) The Discovery of Grounded Theory: Strategies for Qualitative Research. Aldine Pub. Co.

Glikson E, Woolley AW (2020) Human Trust in Artificial Intelligence: Review of Empirical Research. Acad. Manag. Ann. 14(2): 627-660.

Hansson SO (2018) How to perform an ethical risk analysis. Risk Analysis. 38(9):1820-1829.

Hinds PJ, Bailey DE (2003) Out of sight, out of sync: Understanding conflict in distributed teams. Organ. Sci. 14(6):615-632.

Hirschman AO (1970) Exit, Voice, and Loyalty: Response to Decline in Firms, Organizations, and States. Harvard University Press.

Hirschhorn L (1984) Beyond Mechanization. MIT Press, Cambridge, Mass.

Jasper JM (2011) Emotions and social movements: Twenty years of theory and research. Annual Rev. Sociol. 37:285-303.

Kahn WA (2019) Dynamics and Implications of Distress Organizing. Acad. Management J. 62(5):14711497.

Klein J, Amis J (2020) The Dynamics of Framing: Image, Emotion, and the European Migration Crisis. Acad. Management J. forthcoming

Kellogg K, Valentine M, Christin A (2019) Algorithms at work: The new contested terrain of control. Acad. Manag. Ann.14(1):366-410.

Klein K, Boals A (2001) Expressive writing can increase working memory capacity. J. Exp. Psychol. 130(3):520-533.

Kreuzer M (2014) Remotely Piloted Aircraft: Evolution, Diffusion, and the Future of Air Warfare. Princeton, NJ : Princeton University

Kroll J, Egan E (2004) Psychiatry, moral worry, and moral emotions. J. Psychiatr. Pract. 10:352-60. Kunda G (2006) Engineering culture: Control and commitment in a high-tech corporation, Revised 
Edition. Philadelphia, PA: Temple University Press

Leonardi PM, Barley SR (2010) What's under construction here? Social action, materiality, and power in constructivist studies of technology and organizing. Acad. Management Ann. 4(1):1-51.

Leonardi PM, Treem JW (2020) Behavioral Visibility: A new paradigm for organization studies in the age of digitization, digitalization, and datafication. Organ. Stud. 41(12):1601-1625.

Leonardi PM (2021) COVID-19 and the New Technologies of Organizing: Digital Exhaust, Digital Footprints, and Artificial Intelligence in the Wake of Remote Work. J. Manag. Stud. 58:1.

Lincoln YS, Guba EG (1985) Naturalistic Inquiry. Sage Publications.

Locke K (2001) Grounded Theory in Management Research. Sage Publications.

Mazmanian M (2013). Avoiding the trap of constant connectivity: When congruent frames allow for heterogeneous practices. Acad. Management J. 56(5):1225-1250.

Mazmanian M, Orlikowski WJ, Yates J (2013) The Autonomy Paradox: The Implication of Mobile Email Devices for Knowledge Professionals. Organ Sci. 24(5):1337-1357.

Möhlmann M, Zalmanson L, Henfridsson O, Gregory RW (2020) Algorithmic management of work on online labor platforms: When matching meets control, MIS Quarterly.

Nord WR, Brief AP, Atieh JM, Doherty EM (1990). Studying meanings of work: the case of work values," in Issues in Organization and Management Series. Meanings of Occupational Work: A Collection of Essays, eds AP Brief, WR. Nord (Lexington Books/D. C. Heath and Com), 21-64.

Nurmi N, Hinds PJ (2020) Work design for global professionals: Connectivity demands, connectivity behaviors, and their effects on psychological and behavioral outcomes. Organ. Stud. 41(2):16971724.

O'Neill OA, Rothbard N (2017) Is love all you need? The effects of emotional culture, suppression, and work-family conflict on firefighter risk-taking and health. Acad. Management J. 60(1):78-108.

Oreg S, Bartunek J, Lee G, Do B (2018). An affect-based model of recipients' responses to organizational change events. Acad. Manag. Rev. 43:65-86.

Pachidi S, Berends H, Faraj S, Huysman M (2020) Make way for the algorithms: Symbolic actions and change in a regime of knowing. Organ Sci. 32(1):18-41.

Perrow C (1983) The organizational context of human factors engineering. Admin. Sci. Quart. 28(4):521541.

Perrow C (1999) Normal Accidents: Living with High-Risk Technologies. Princeton University Press, Princeton, NJ.

Petriglieri G, Ashford SJ, Wrzesniewski A (2019) Agony and ecstasy in the gig economy: Cultivating holding environments for precarious and personalized work identities. Admin. Sci. Quart. 64(1):124170. 
Pratt MG (2000) The good, the bad, and the ambivalent: Managing identification among Amway distributors. Admin. Sci. Quart. 45:456-493.

Pratt MG, Doucet L (2000) Ambivalent feelings in organizational relationships. Fineman S, ed. Emotions in Organizations (Sage, London) 204-226.

Pratt MG (2008) Fitting oval pegs into round holes tensions in evaluating and publishing qualitative research in top-tier North American journals. Organ. Res. Methods. 11(3):481-509.

Radcliffe LS (2017) Capturing the complexity of daily workplace experiences using qualitative diaries. In C. Cassel, A. Cuncliffe G. Grandy (Eds.), The SAGE Handbook of Qualitative Business and Management Research Methods (pp. 188-204). Sage Publications.

Rauch M, Ansari S (2021) Diaries as a methodological innovation for studying grand challenges. Res. Sociol. Organ. In press

Rogers J (2019) The dark side of our drone future. Bulletin of the Atomic Scientists. https://thebulletin.org/2019/10/the-dark-side-of-our-drone-future/

Rosso BD, Bekas KH, Wrzesniewski A (2010). On the meaning of work: A theoretical integration and review. Res Organ Behav. 30:91-127.

Sanchez-Burks J, Huy QN (2009) Emotional aperture and strategic change: The accurate recognition of collective emotions. Organ. Sci. 20(1): 22-34.

Schabram K, Maitlis S (2017). Negotiating the challenges of a calling: Emotion and enacted sensemaking in animal shelter work. Acad. Management J. 60(2): 584-609.

Schwarz E (2018) Death Machines: The Ethics of Violent Technologies. Manchester University Press.

Schwartz SH (1992) Universals in the content and structure of values: Theoretical advances and empirical tests in 20 countries. In Zanna (Ed.), Advances in experimental social psychology, Vol. 25, 1-65).

Strauss A, Corbin J (1998) Basics of Qualitative Research: Techniques, and Procedures for Developing Grounded Theory. 2nd ed. Sage Publications.

Taylor SJ, Bogdan R (1984) Introduction to Qualitative Research Methods: The Search for Meaning (2nd ed.). Wiley

Thompson J, Bunderson J (2003) Violations of Principle: Ideological Currency in the Psychological Contract. Acad. Management Rev. 28(4):571-586.

United Nations (2020) Report of the Special Rapporteur on extrajudicial, summary, or arbitrary executions to the Human Rights Council. URL: https://documents-ddsny.un.org/doc/UNDOC/GEN/G20/211/32/PDF/G2021132.pdf?OpenElement

Van de Ven AH, Poole MS (1990) Methods for studying innovation development in the Minnesota Innovation Research Program. Organ. Sci. 1(3):313-335.

Vertesi J (2014) Seeing Like a Rover How Robots, Teams, and Images Craft Knowledge of Mars. 
University of Chicago Press, US.

von Krogh G (2018) Artificial Intelligence in organizations: New opportunities for phenomenon-based theorizing. Acad. Management Dis. 4(4):404-409.

von Krogh GV, Haefliger S, Spaeth S, Wallin MW (2012) Carrots and Rainbows: Motivation and Social Practice in Open Source Software Development. MIS Q. 36(2):649-676.

Voronov M, Vince R (2012) Integrating emotions into the analysis of institutional work. Acad. Management Rev. 37(1):58-81.

Voronov M, Weber K (2016) The heart of institutions: Emotional competence and institutional actorhood. Acad. Management Rev. 41(3):456-478.

Weick KE (1979) The social psychology of organizing (2nd ed.). Reading, MA: Addison-Wesley. Wrzesniewski A (2012) Callings. The Oxford handbook of positive organization scholarship. Zerubavel E (1991) The fine line: Making distinctions in everyday life. New York: Free Press Zietsma C, Toubiana M, Voronov M, Roberts A (2018) Emotions in Organization Theory. Cambridge University Press

Zuboff S (1988) In the Age of the Smart Machine: The Future of Work and Power. Basic Books, New York.

Zuboff S (2019) The Age of Surveillance Capitalism: The Fight for a Human Future at the New Frontier of Power. Public Affairs. 
Figure 1: A model of technology-induced emotional ambivalence and strategies for coping with it

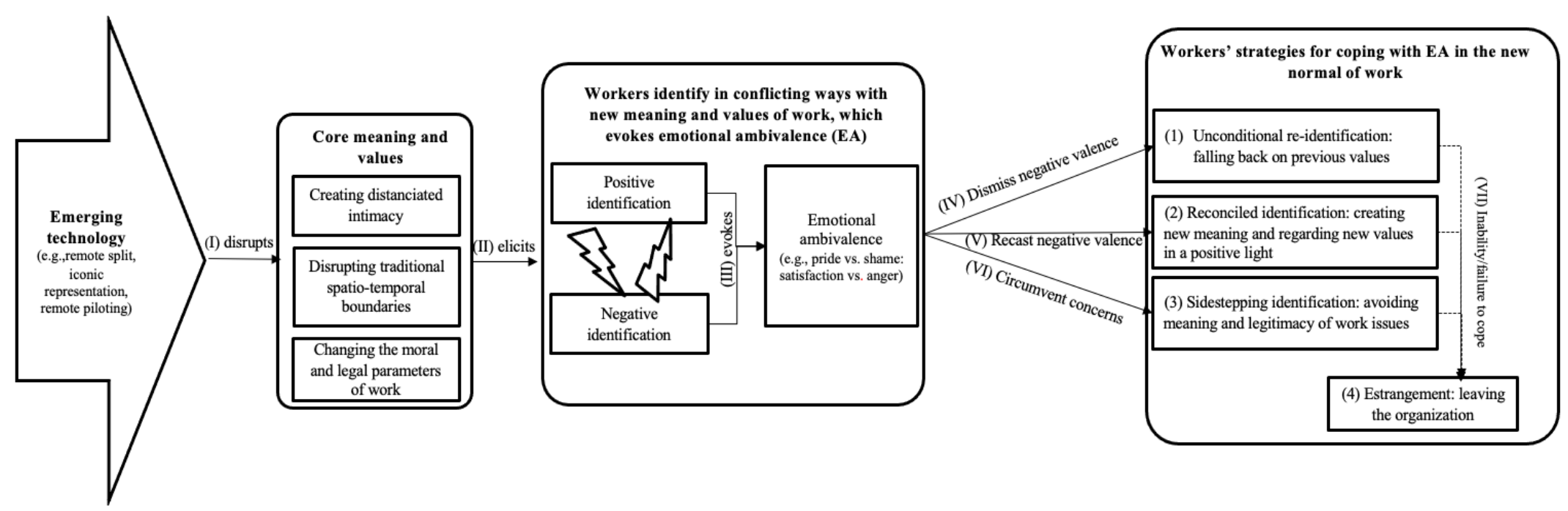


Table I. Overview of Data Sources

Data type Details

Interviews (43)

- 43 interviews with 43 informants from all hierarchical levels, and with differing levels of involvement, experience, and responsibility within the drone program, including drone operators, drone pilots, drone technicians, and support staff.

- 39 interviews were audio-recorded and professionally transcribed verbatim, and four interviewees preferred not to be taped, in which case we took extensive notes.

- Note: In order to facilitate easier reading of the manuscript, we assigned interviews and diaries numbers from 1 to 43. Each informant was assigned a particular number, (e.g., 22), which then was used both for the interview and diary (Interview 22 and Diary 22).

Diaries (43)

- 43 personal diaries written by former and current U.S. air force personnel from all hierarchical levels and with different roles within the drone program: drone operators, drone pilots, drone technicians, and support staff.

- All the diaries were transcribed electronically if written by hand (14).

- The diaries were written voluntarily, not as part of a research project, and were not handed over to anybody else (including the U.S. Air force). Diaries are personal and thus address many private matters not relating to the individuals' work (e.g., their family life and other events).

- The diaries vary in style and in the degree of detail; they also vary in terms of how long they were kept, ranging from six months to 12 years of daily journaling.

Ethnographical observations (279.5 hrs)

Documents $(2,937)$
- Observations of daily activities on a U.S. air force military base involved in the drone program, which were recorded in detailed field notes (125 hrs).

- Observations of informal gatherings (e.g., barbecues or drinking a beer together) of group workers off-site at the military base; these were recorded in detailed field notes (23.5 hrs).

- Observations of informal gatherings of group members discussing daily business, also recorded in detailed field notes $(23.5 \mathrm{hrs})$.

- Observations of training, meetings, and other activities undertaken as preparation for visiting the military base (120 hrs).

- Observations of presentations at public talks and panel discussions, recorded in detailed field notes (11 hrs).

- Internal documentation, including reports, summaries, and interim reports on selected projects (569).

- PowerPoint presentations to various entities (76).

- Documentation relating the drone program prepared for the U.S. Senate (313).

- Training material for new employees and training curricula for newly created job positions and training procedures for the drone program (693).

- Publicly available media coverage of the drone program (830).

- Videos recorded for training purposes (33).

- Miscellaneous organizational documents relating to the drone program (423). 


\section{Table II. Illustrative Supporting Data}

\section{Category Representative quotes}

"We need hundreds of people to make one Reaper ready to roam. Much more people involved than you can Remote-split operations imagine from US Florida, here, Germany, Afghanistan, satellites - you name it." (Interview 11)

"It is a tight network of coordination and things to get one reaper up in the air." (Interview 31)

Remote piloting of unmanned vehicles

Interaction through iconic representation

Creating distanciated intimacy

Disrupting traditionally conceived spatiotemporal boundaries

Changing moral and legal parameters of work

Positive identification

"Removed the pilot from the sky to the ground." (Interview 21)

"I control the national bird of Afghanistan [nickname for drone] from my living room to play big brother." (Interview 19)

"I see them [objects on the screen] as small creatures on the ground similar to a black and white movie." (Field note 10)

"Black and white tiny partials down thousands of feet and thousands of miles from me." (Diary 11)

"We have now new relationships with the objects we target and surveil. It's like Big Brother, just in the military sense." (Interview 11)

"I spy on total strangers without knowing exactly what I am looking for." (Informal conversation 26)

"Enabled by the technology, I am sitting in my chair 25 minutes from my house and at the same time I watch fuckers in Afghanistan." (Interview 18)

"There are simply no boundaries anymore. We are at work 24/7/365 from our own homes." (Diary 33)

"I have never talked to a lawyer in my entire life until this new assignment." (Interview 19)

"This moral stuff and questions are all new to me." (Field note 49)

"The technology allows us to fulfill our mission goals." (Interview 10)

"Makes me proud that we can fight the war on terror now back at home while staying safe." (Interview 07)

"UAV takes the essence out of being a soldier." (Diary 20)

Negative identification "It takes out all what we stand for and hold dear for decades. We are cowards now. There is a lots of questioning of fit going on now." (Interview 19)

"Where is up and down? Have very mixed feelings about work." (Diary 21)

Emotional ambivalence "Who is good? Who is bad? Very blurry, all our involvement here." (Interview 10) (Diary 40)

"It's not about only protecting Americans but also protecting locals and helping children to go to school. This is why we are doing drones now much more." (Informal conversation 10)

Reconciled identification "This war is bigger than just the US. We help local communities in Afghan to prosper." (Diary 25) "It's just a different technology that does the same [functionality]. I ignore my emotions." (Interview 27)

Unconditional reidentification

"It is the responsibility of others to make decisions who we target. I am just the one who exercises what has been decided after lengthy processes and mountains of information." (Interview 18)

"We are the best country in the world. Who am I questioning authority and chain of command? All the whistleblowers are traitors working for the enemy, giving away valuable intel. [...] I am a soldier protecting our nation." (Interview 04)

"I follow orders. Those idiots that question our chain of command are losers." (Diary 08)

Sidestepping identification

"The military is just another job for me." (Field note 59)

"I focus on the paycheck and don't bother about what I am actually doing." (Interview 41)

"The army is my employer, not God or my wife. They pay my bills and that's it." (Interview 42)

"There is no glory in killing other people from a cubicle far away." (Diary 22)

"Just lies, deception, secrets, and more secrets. Everything in the name of Uncle Sam. [...] This is no way

Estrangement of living. My wage is paid to kill people." (Interview 23)

"Moment we targeted a wedding knew I couldn't do this any longer. Wedding the alleged happiest day of your life and we don't have any better idea than to nuke them?" (Diary 42) 
Table III. Overview of workers and their response strategies

\begin{tabular}{|c|c|c|c|c|c|c|}
\hline ID & Gender & Position & $\begin{array}{c}\text { Previous } \\
\text { military } \\
\text { experience }\end{array}$ & $\begin{array}{c}\text { Military } \\
\text { family }\end{array}$ & Response strategy $\left(t_{1}\right)$ & Response strategy $\left(t_{2}\right)$ \\
\hline 1 & male & technician & yes & yes & (1) unconditional re-identification & (1) unconditional re-identification \\
\hline 2 & female & operator & yes & yes & (1) unconditional re-identification & (4) estrangement \\
\hline 3 & male & operator & yes & yes & (1) unconditional re-identification & (1) unconditional re-identification \\
\hline 4 & male & technician & yes & no & (1) unconditional re-identification & (4) estrangement \\
\hline 5 & male & operator & yes & yes & (1) unconditional re-identification & (1) unconditional re-identification \\
\hline 6 & female & operator & yes & yes & (1) unconditional re-identification & (1) unconditional re-identification \\
\hline 7 & male & operator & yes & no & (1) unconditional re-identification & (1) unconditional re-identification \\
\hline 8 & female & operator & yes & yes & (1) unconditional re-identification & (1) unconditional re-identification \\
\hline 9 & male & pilot & yes & yes & (1) unconditional re-identification & (1) unconditional re-identification \\
\hline 10 & male & pilot & yes & yes & (1) unconditional re-identification & (1) unconditional re-identification \\
\hline 11 & male & operator & yes & yes & (1) unconditional re-identification & (1) unconditional re-identification \\
\hline 12 & female & pilot & yes & no & (1) unconditional re-identification & (1) unconditional re-identification \\
\hline 13 & male & operator & yes & no & (1) unconditional re-identification & (4) estrangement \\
\hline 14 & female & technician & yes & no & (1) unconditional re-identification & (1) unconditional re-identification \\
\hline 15 & female & operator & yes & yes & (1) unconditional re-identification & (1) unconditional re-identification \\
\hline 16 & male & support & yes & yes & (1) unconditional re-identification & (1) unconditional re-identification \\
\hline 17 & male & technician & yes & yes & (1) unconditional re-identification & (1) unconditional re-identification \\
\hline 18 & male & pilot & yes & yes & (1) unconditional re-identification & (1) unconditional re-identification \\
\hline 19 & male & pilot & yes & yes & (1) unconditional re-identification & (1) unconditional re-identification \\
\hline 20 & male & operator & yes & no & (1) unconditional re-identification & (4) estrangement \\
\hline 21 & male & pilot & yes & yes & (1) unconditional re-identification & (1) unconditional re-identification \\
\hline 22 & male & operator & yes & yes & (2) reconciled identification & (4) estrangement \\
\hline 23 & male & operator & yes & yes & (2) reconciled identification & (4) estrangement \\
\hline 24 & male & operator & yes & no & (2) reconciled identification & (2) reconciled identification \\
\hline 25 & male & pilot & yes & no & (2) reconciled identification & (2) reconciled identification \\
\hline 26 & female & operator & yes & yes & (2) reconciled identification & (2) reconciled identification \\
\hline 27 & male & pilot & yes & yes & (2) reconciled identification & (4) estrangement \\
\hline 28 & male & operator & yes & yes & (2) reconciled identification & (2) reconciled identification \\
\hline 29 & female & support & yes & yes & (2) reconciled identification & (2) reconciled identification \\
\hline 30 & female & operator & yes & yes & (2) reconciled identification & (2) reconciled identification \\
\hline 31 & male & pilot & yes & yes & (2) reconciled identification & (4) estrangement \\
\hline 32 & male & operator & yes & no & (2) reconciled identification & (2) reconciled identification \\
\hline 33 & male & pilot & yes & yes & (2) reconciled identification & (2) reconciled identification \\
\hline 34 & male & operator & yes & yes & (2) reconciled identification & (2) reconciled identification \\
\hline 35 & female & operator & yes & yes & (2) reconciled identification & (2) reconciled identification \\
\hline 36 & male & operator & yes & yes & (2) reconciled identification & (2) reconciled identification \\
\hline 37 & male & operator & no & no & (3) sidestepping identification & (4) estrangement \\
\hline 38 & male & operator & no & no & (3) sidestepping identification & (4) estrangement \\
\hline 39 & female & operator & no & yes & (3) sidestepping identification & (4) estrangement \\
\hline 40 & male & technician & no & no & (3) sidestepping identification & (3) sidestepping identification \\
\hline 41 & male & pilot & no & no & (3) sidestepping identification & (4) estrangement \\
\hline 42 & male & pilot & no & yes & (3) sidestepping identification & (4) estrangement \\
\hline 43 & female & operator & no & no & (3) sidestepping identification & (4) estrangement \\
\hline
\end{tabular}




\section{Figure 2: Data structure}

Contact with different units for operations

Dividing activities across the globe

New collaborations and communication requirements across the globe

Humans (e.g., insurgents, friendlies, and own troops) are displayed in real time

Constant exchange of intelligence and need for decision-making based on iconic representation

Contact to other people only via screens, chat, and phone

Pilots removed from the cockpit in the sky to the cockpit on the ground

Playing with a bunch of computers and a joystick

I am a joystick pilot in a simulation called war

Being in two places at the same time

Ability to follow insurgents on the ground from a safe "office" state-side

Possibility of forging new (social) relations with those being observed and targeted

Disruption to home-work life and "batch" living and attributions of total institution

Ability to take part in civilian life and war

Concept of war moves from a temporary to a constant wa

Perception refuting traditional morals in drone war

Raising questions of appropriate military criteria and definitions of targets

Increased media attention on legality of war

Pride in the technological capabilities of the drones

Happiness about having "no more funerals to go to"

New possibilities for civilian life and work-life-balance

Appalled by the requirement to watch people die, particularly children and women

Feeling distrust and betrayal because of lack of information and loss of the brotherhood

Unfavorable feelings and anguish because of having 'no more skin in the game'

Falling back on entrenched values by justifying despite change in work context

Showing unwavering support for the organization

Creating new values of work or recasting them in a positive light

Achieving realignment between oneself and the organization by creating a new meaning of work

Avoiding negative experiences, emotions, and thoughts

Ignoring the legitimacy aspect of work issues

Ignoring issues of other members and focusing on oneself

Focusing on the money and paycheck, and other personal benefits of work

"Was time for me to get out of here" [the Air Force]

Mental health regarded as more important than salary check

Exiting the organization as no longer able to handle the work

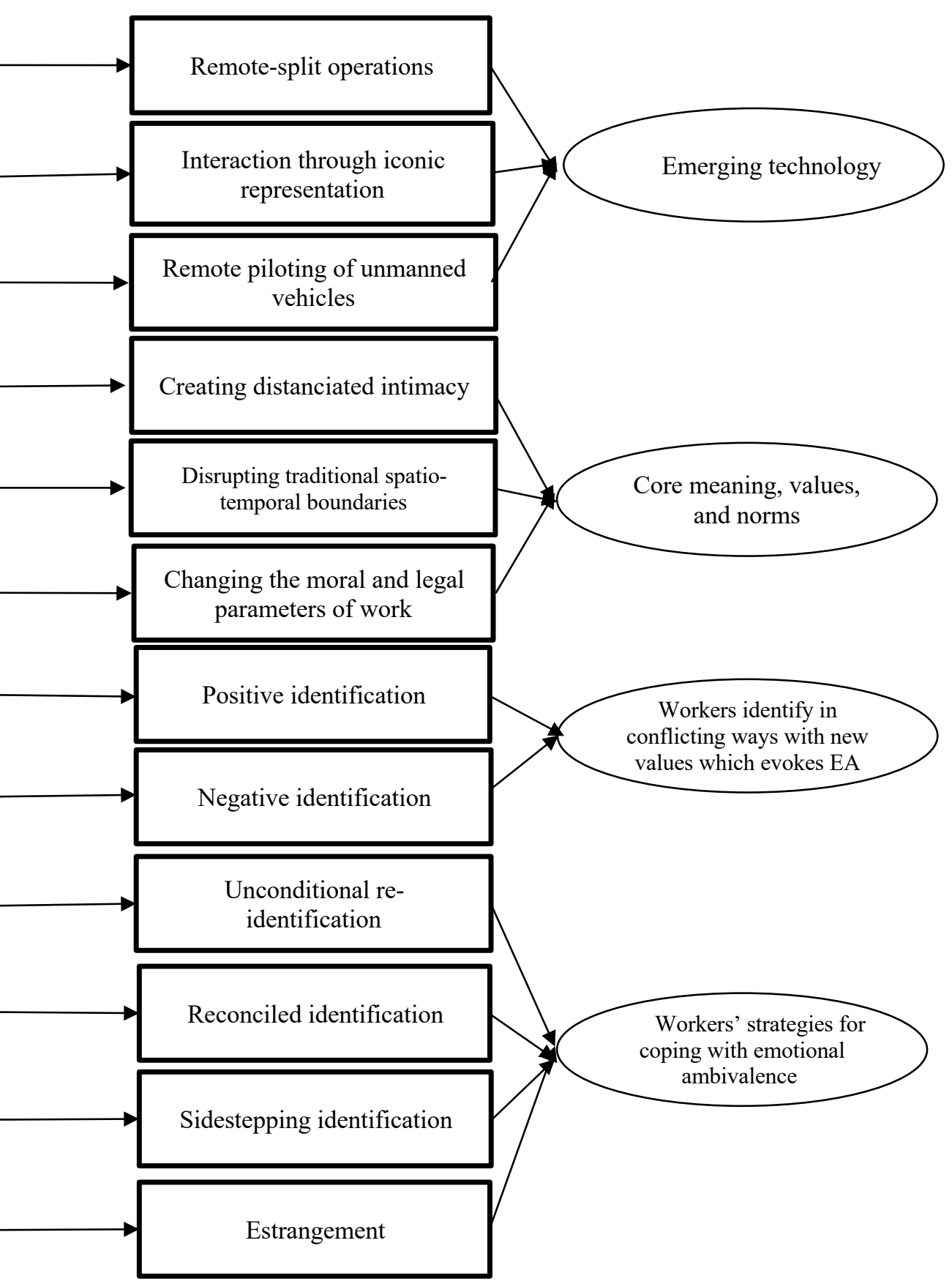

